\title{
Effects of mechanical layering on hydrofracture emplacement and fluid transport in reservoirs
}

\author{
Sonja L. Philipp ${ }^{1}$ *, Filiz Afşar ${ }^{1}$ and Agust Gudmundsson ${ }^{2}$ \\ ' Department of Structural Geology and Geodynamics, Geoscience Centre, University of Göttingen, Göttingen, Germany \\ ${ }^{2}$ Department of Earth Sciences, Royal Holloway University of London, Egham, UK
}

\section{Edited by:}

Valerio Acocella, Università Roma

Tre, Italy

\section{Reviewed by:}

Marco Neri, Istituto Nazionale di Geofisica e Vulcanologia, Italy

Shigekazu Kusumoto, University of

Toyama, Japan

${ }^{*}$ Correspondence:

Sonja L. Philipp, Department of

Structural Geology and

Geodynamics, Geoscience Centre,

University of Göttingen,

Goldschmidtstrasse 3, D-37077

Göttingen, Germany

e-mail:sonja.philipp@

geo.uni-goettingen.de
Fractures generated by internal fluid pressure, for example, dykes, mineral veins, many joints and man-made hydraulic fractures, are referred to as hydrofractures. Together with shear fractures, they contribute significantly to the permeability of fluid reservoirs such as those of petroleum, geothermal water, and groundwater. Analytical and numerical models show that-in homogeneous host rocks-any significant overpressure in hydrofractures theoretically generates very high crack tip tensile stresses. Consequently, overpressured hydrofractures should propagate and help to form interconnected fracture systems that would then contribute to the permeability of fluid reservoirs. Field observations, however, show that in heterogeneous and anisotropic, e.g., layered, rocks many hydrofractures become arrested or offset at layer contacts and do not form vertically interconnected networks. The most important factors that contribute to hydrofracture arrest are discontinuities (including contacts), stiffness changes between layers, and stress barriers, where the local stress field is unfavorable to hydrofracture propagation. A necessary condition for a hydrofracture to propagate to the surface is that the stress field along its potential path is everywhere favorable to extension-fracture formation so that the probability of hydrofracture arrest is minimized. Mechanical layering and the resulting heterogeneous stress field largely control whether evolving hydrofractures become confined to single layers (stratabound fractures) or not (non-stratabound fractures) and, therefore, if a vertically interconnected fracture system forms. Non-stratabound hydrofractures may propagate through many layers and generate interconnected fracture systems. Such systems commonly reach the percolation threshold and largely control the overall permeability of the fluid reservoirs within which they develop.

Keywords: hydrofracture propagation, mechanical layering, fluid transport, local stresses, fluid reservoirs, hydrofracture emplacement

\section{INTRODUCTION}

A hydrofracture is a fracture partly or wholly generated by internal fluid pressure. The term "hydrofracture" is well-established for fluid-driven rock fractures, including mineral veins and (igneous and clastic) dykes, as well as many joints (e.g., Davis, 1983; Rummel, 1987; Sleep and Fujita, 1997; Rijsdijk et al., 1999; Bons, 2001; Gudmundsson, 2011a; Gundersen et al., 2011; Bons et al., 2012). Hydraulic fractures that is, man-made fractures generated by fluid overpressure and injected into reservoir rocks to increase their permeabilities (e.g., Hubbert and Willis, 1957; Charlez, 1997; Yew, 1997; Mahrer, 1999; Economides and Nolte, 2000), are also considered hydrofractures.

Even if the fluid properties of oil, water, and magma (particularly their densities and viscosities) are quite different, the basic physical principles are the same for all kinds of hydrofractures (cf. Mandl, 2005). In many hydrofractures, for example those generated by gas, oil, or groundwater pressure or manmade hydraulic fractures, the fluid may disappear (diffuse or flow out) after the fracture has formed. This is presumed to be the case for the formation of many joints, as initially suggested by Secor (1965). Other hydrofractures, including dykes and mineral veins are driven open by fluids that solidify or precipitate in the fracture once it has formed. In the latter case the fracture tips, and the mechanisms of fracture emplacement, can be more easily studied. Studies of their cross-cutting relationships (where the relative displacements of fractures cut by later fractures are considered) indicate that most paleohydrofractures are extension fractures (e.g., Gudmundsson et al., 2002). Since outcrop-scale absolute tension cannot occur at depths greater than a few hundred meters (Twiss and Moores, 2006), most extension fractures, in turn, could only be formed as hydrofractures.

Hydrofracture paths are major conduits for fluid transport in the crust. Therefore, the conditions of hydrofracture emplacement are of vital importance in fields such as gas, petroleum, and geothermal exploration, waste studies, seismology, volcanology, hydrogeology, and $\mathrm{CO}_{2}$-sequestration (e.g., Bonafede and Danesi, 1997; Ingebritsen and Sanford, 1998; Hardebeck and Hauksson, 1999; Dahm, 2000; Economides and Nolte, 2000; Cobbing and 
O'Dochartaigh, 2007; Chiaramonte et al., 2008). In fact, the formation of hydrofractures is one of the main mechanisms for the generation and maintenance of permeability, particularly in fluid-filled heterogeneous reservoirs such as those associated with petroleum, groundwater, volcanic, and geothermal fields. Although the dynamics of fluid accumulation and transport in fractured reservoirs are topics of great current interest (e.g., Coward et al., 1998; Rossmanith, 1998; Faybishenko et al., 2000; Kümpel, 2003; Lonergan et al., 2007; van Golf-Racht, 2009; Bourbiaux, 2010; Spence et al., 2013), the formation of hydrofractures and their potential effects on permeability have received less attention than they deserve.

When a reservoir consists of numerous layers, stratabound hydrofractures contribute little if anything to its overall vertical permeability. For such a reservoir, the permeability is necessarily dominated by fractures that propagate through many layers that is, non-stratabound fractures. In volcanic hazard studies the propagation of magma-driven fractures (dykes) outside, rather than inside, the reservoirs is of importance. Composite volcanoes are layered, and the layers often have contrasting mechanical properties (Gudmundsson, 2006). Some of these layers develop local stresses which are unfavorable to dyke propagation. Consequently, most dykes become arrested and never reach the surface to feed volcanic eruptions (Stewart et al., 2003; Gudmundsson and Brenner, 2005; Gudmundsson, 2006; Martí and Geyer, 2009).

Growth of a hydrofracture depends on its fluid pressure as well as on the mechanical properties of the host rock. Many models of hydrofracture propagation assume the mechanical properties of the host rock to be homogeneous and isotropic (Spence and Turcotte, 1985; Lister and Kerr, 1991; Rubin, 1995; Flekkoy et al., 2002; Al-Busaidi et al., 2005). These assumptions make the problem mathematically tractable, and the resulting analytical models highlight the basic physics involved in hydrofracture development. These models are, however, of limited applicability to fluid reservoirs composed of heterogeneous and anisotropic rocks. In reservoirs, heterogeneities range in sizes from grains to entire basins. But for the propagation of hydrofractures perhaps the most important heterogeneity in reservoirs is mechanical layering (Economides and Nolte, 2000).

In this paper we explore the effects of mechanical layering in fluid reservoirs on the emplacement of hydrofractures and thus their ability to transport fluids. First, we review models of fractures in reservoirs and fluid transport in fractured rocks and faults. Second, we review analytical and numerical models on the initiation and propagation of hydrofractures. In particular, we present models on fluid overpressures of hydrofractures, and crack-tip tensile stresses. Third, we discuss mechanical layering in reservoirs and its effects on hydrofracture emplacement. We present field examples of hydrofractures affected by mechanical layering and compare with numerical models.

\section{RESERVOIR FRACTURES AND FLUID TRANSPORT MODELS OF RESERVOIR FRACTURES}

Fractures control the permeability of many reservoirs and the relation between fracturing and fluid flow is currently a topic of extensive research (e.g., Vigneresse, 2001; Berkowitz, 2002;
Labaume et al., 2002; Neuzil, 2003; Dietrich et al., 2005; Dresen et al., 2006; Sahimi, 2011; Adler et al., 2012). Fractures are very efficient paths for the migration of hydrocarbons in reservoirs (Mandl and Harkness, 1987; Aydin, 2000; Nunn and Meulbroek, 2002). A rock body with fractures that have significant effect on its fluid transport is a "fractured reservoir" (Nelson, 1985, 2001; Aguilera, 1995).

Rock fractures may be classified in various ways (e.g., Stearns and Friedman, 1972; Nelson, 1985; Price and Cosgrove, 1990; Priest, 1992; Davis and Reynolds, 1996; van der Pluijm and Marshak, 2003; Twiss and Moores, 2006; Gudmundsson, 2011a). Depending on the relative displacement across the fracture plane, however, all reservoir fractures are either extension fractures or shear fractures. Extension fractures include tension fractures (formed in absolute tension) and hydrofractures. For extension fractures, the relative displacement is perpendicular to, and away from, the fracture plane. For shear fractures the relative displacement is parallel to the fracture plane. Shear fractures with significant or large displacements are commonly referred to as faults.

For modeling rock fractures in reservoirs, three crack modes are used (Figure 1; e.g., Broberg, 1999). Extension fractures are modeled as mode I cracks (Figure 1). Shear fractures are modeled as either mode II or mode III cracks depending on whether the crack-tip displacement is perpendicular or parallel to the leading edge (tip) of the crack (Figure 1). The various combinations of these basic types include mixed-mode cracks ("hybrid cracks") where, commonly, mode I displacement is mixed with either mode II or mode III displacement (Hudson and Harrison, 1997).

The displacement on a crack is largely determined by its controlling dimension (Gudmundsson, 2000b). The controlling dimension is the smaller of the strike and dip dimension. The horizontal (strike) dimension of a fracture, measured as linear distance between its ends in a lateral outcrop, is referred to as its length, the vertical (dip) dimension as its height (Figure 2). The maximum thickness or fracture dimension measured perpendicular to the fracture walls is the aperture or opening of the fracture (Figure 2). That is, if the height is smaller than the

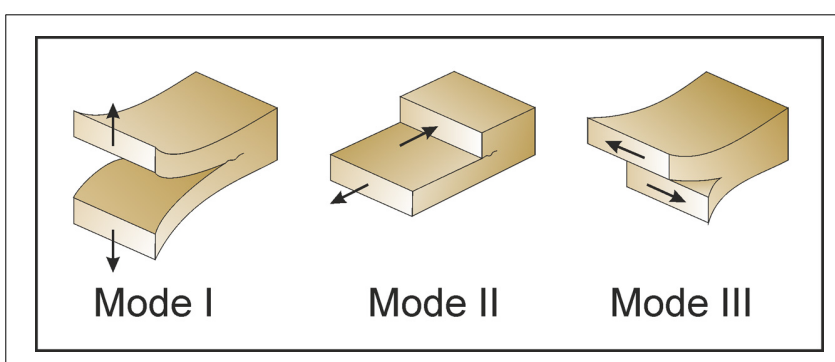

FIGURE 1 | Crack modes used in modeling rock fractures in a reservoir: In a mode I crack, the relative displacement is perpendicular to, and away from, the fracture plane (extension fractures). In mode II and III crack-tip displacement is parallel to the fracture plane: in mode II perpendicular, in III parallel to the leading edge (tip) of the crack. There are various combinations of these basic types (modified from Hudson and Harrison, 1997). 


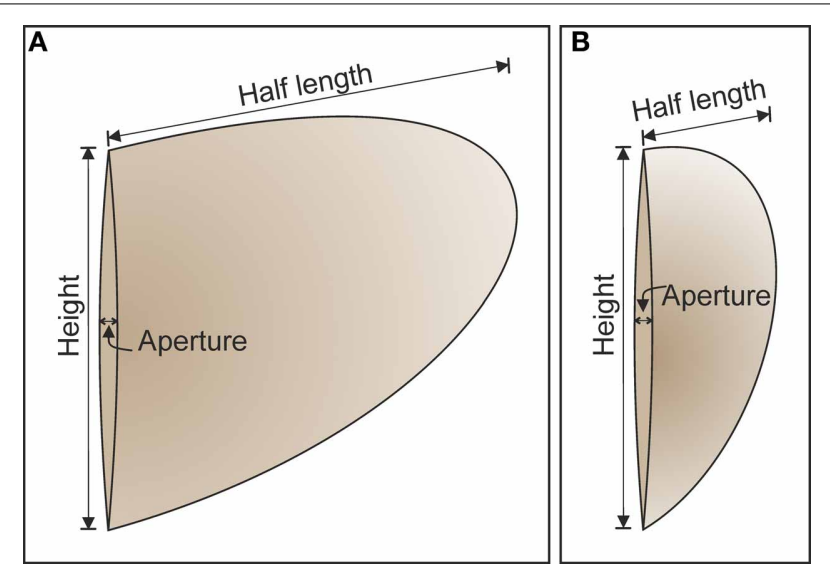

FIGURE 2 | The length of a fracture is its horizontal (strike) dimension, its height is the vertical (dip) dimension, and its aperture is the maximum thickness measured perpendicular to the fracture walls. (A) If the height is smaller than the length, the fracture aperture is correlated to the fracture height. (B) If the height is larger than the length, the fracture aperture correlates with the fracture length. The smaller of the strike and dip dimension is therefore referred to as the controlling dimension of the fracture (modified from Gudmundsson, 2000b).

length (Figure 2A), the fracture aperture is correlated with the fracture height. If, however, the height is larger than the length (Figure 2B), the fracture aperture correlates with the fracture length.

As regards shape, any simple two-dimensional fracture (when the aperture and its variation are neglected) can be modeled as one of three basic ideal elastic crack types (Figure 3; Atkins and Mai, 1985): (i) through crack (a through-the-thickness crack) that extends through the whole layer containing the crack, from one free rock surface to another; (ii) part-through crack (a thumbnail crack) that extends from a free surface of the rock body and partly into it; and (iii) interior crack is elliptical and located in the interior of the rock body hosting the crack, the body being regarded as infinite. The penny-shaped crack is the special case of a circular interior crack. Before stress/pressure causes displacement of the crack surfaces, the cracks are regarded as mathematical that is, the aperture is effectively zero.

\section{FLUID FLOW IN FRACTURED ROCKS}

In most solid low-porosity rocks, fluid flow occurs primarily through the fractures that form later than the host rocks themselves and constitute a secondary porosity (Nelson, 1985; Singhal and Gupta, 1999). Despite its importance, fluid flow in fractured rocks is still not well-understood (e.g., Singhal and Gupta, 1999; Faybishenko et al., 2000; Berkowitz, 2002).

When modeling fluid flow in a single, isolated fracture, the fracture is often idealized as having smooth, parallel walls (Figure 4). For such a fracture, a special solution of the NavierStokes equations for the flow of a viscous fluid is commonly used. This solution predicts that the volumetric flow rate is proportional to the cube of the aperture of the fracture through which the fluid flows. Particularly in hydrogeology, this solution is referred to as the "cubic law" (de Marsily, 1986).

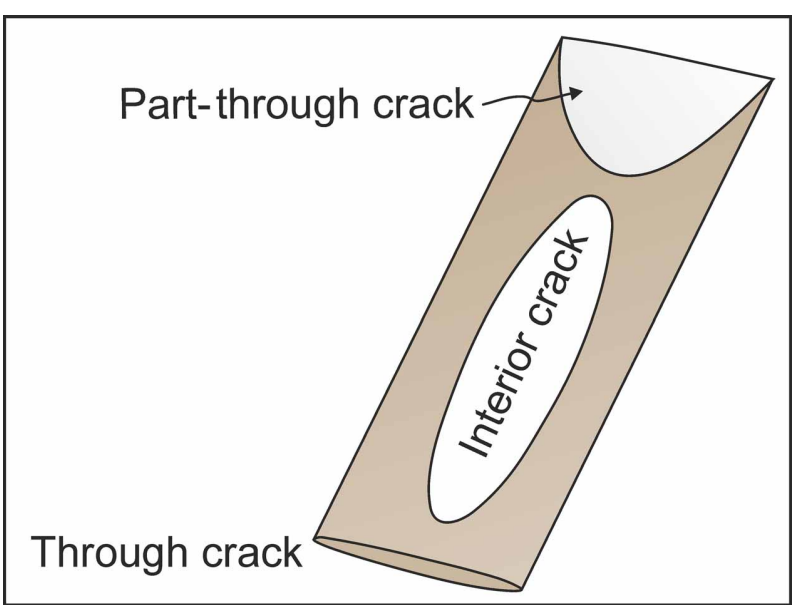

FIGURE 3 | Crack shapes of idealized two-dimensional fractures (when the aperture is neglected) used in modeling rock fractures in a reservoir: A through crack extends through the whole layer containing the crack, from one free rock surface to another. A part-through crack extends from a free surface of the rock body and partly into it. An interior crack is elliptical and located in the interior of the rock body hosting the crack, the body being regarded as infinite (modified from Gudmundsson, 2000b).

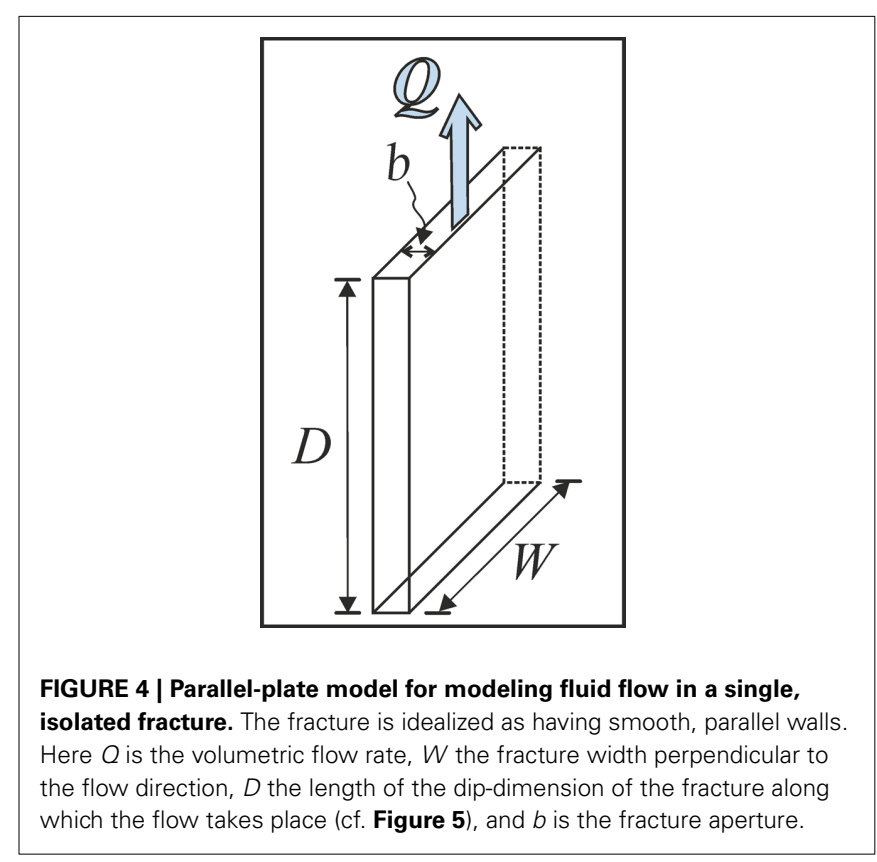

The host-rock is normally assumed to respond to fluid flow in a fracture in one of two basic ways: rigidly or elastically (Figure 5). In many models of fluid flow in rock fractures in the uppermost part of the crust, the host rock is assumed to be perfectly rigid, so that it does not deform due to changes in stress or fluid pressure (e.g., Bear, 1993; Taylor et al., 1999). The fracture and its fluid source then behave as self-supporting. This means that when fluid is added to, or withdrawn from, an aquifer or reservoir, so that its pressure changes, the aquifer/reservoir volume remains the same. 


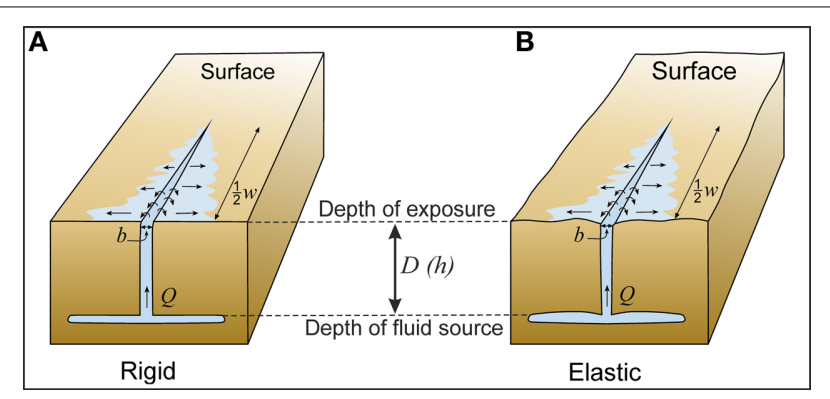

FIGURE 5 | Schematic model of a vertical hydrofracture initiated from a horizontal sill below the present exposure at a depth $h$ below the present exposure. $h$ is the height of a fracture, which for a vertical fracture is equal to its dip dimension $D$ along which fluid flow $Q$ takes place. $W$ is the width of the fracture perpendicular to the flow direction. For a vertical through-going fracture $W$ is equal to its outcrop length $L$. $b$ is the fracture aperture in an outcrop. (A) In a rigid host rock, the fracture and the sill are self-supporting and the shape of a hydrofracture does not depend on its fluid pressure. (B) In an elastic host rock, the shape of a hydrofracture depends on its fluid overpressure, the fracture and the sill deform during fluid transport, and buoyancy has to be taken into account.

In other words, the aquifer/reservoir does not feel the weight of the overburden. Buoyancy, which derives from the weight of the overburden in relation to the weight of a vertical column of a fluid (or, more specifically, the density difference between the host rock and the fluid) has therefore no effects on the pressure gradient of the fluid. The volumetric flow rate $Q_{D}^{s}$, with the superscript $s$ denoting self-supporting fracture and source and the subscript $D$ the length of the dip-dimension of the fracture along which the flow takes place, is given by (Gudmundsson et al., 2002; Gudmundsson, 2011a):

$$
Q_{D}^{s}=\frac{b^{3} W}{12 \mu}\left(\rho_{f} g \sin \alpha-\frac{\partial p_{e}}{\partial D}\right)
$$

where $b$ is the fracture aperture, $W$ the fracture width perpendicular to the flow direction (Figures 4, 5), $\mu$ the dynamic (absolute) fluid viscosity, $\rho_{f}$ the fluid density, $g$ the acceleration due to gravity, $\alpha$ the fracture dip, and $\partial p_{e} / \partial D$ the excess pressure gradient (where the excess fluid pressure $p_{e}$ is the pressure in excess of the minimum principal compressive stress $\sigma_{3}$ in the roof of the source; see section below). For a vertical fracture, the $\operatorname{dip} \alpha=90^{\circ}$, the term $(\sin \alpha)$ becomes 1 and can thus be omitted.

More realistically, the host rock, the fracture, and the fluid source may deform during the fluid transport. For the upper crust, this means that they behave as elastic and the weight of the rock above the source is supported by the fluid pressure in the source. Because the density of the host rock, $\rho_{r}$, is different from that of the fluid, $\rho_{f}$, buoyancy must then be taken into account in Equation (1). The volumetric rate of fluid flow in an elastic fracture (denoted by the superscript $e$ ) is then (Gudmundsson et al., 2002; Gudmundsson, 2011a):

$$
Q_{D}^{e}=\frac{b^{3} W}{12 \mu}\left(\left(\rho_{r}-\rho_{f}\right) g \sin \alpha-\frac{\partial p_{e}}{\partial D}\right)
$$

The cubic law for single fractures can be extended to fracture sets, as has been done for fracture sets in rigid host rocks (Bear, 1993; Singhal and Gupta, 1999).

The use of Equations (1) and (2) can be illustrated with an example of the calculation of the volumetric flow rate through a typical fracture transporting water. We assume smooth parallel fracture walls, so that there is no flow channeling. The fracture occurs at a crustal depth of $3 \mathrm{~km}$, is vertical $\left(\alpha=90^{\circ}\right)$ with a width $W$ (perpendicular to the flow direction) of $500 \mathrm{~mm}$ and an aperture $b$ of $1 \mathrm{~mm}$ (Figure 5). For water at $90^{\circ} \mathrm{C}$ the dynamic viscosity $\mu$ is $3.15 \times 10^{-4} \mathrm{~kg} \mathrm{~m}^{-1} \mathrm{~s}^{-1}$, and the density $\rho_{f}$ is $965 \mathrm{~kg}$ $\mathrm{m}^{-3}$ (Smits, 2000). The acceleration due to gravity $g$ is $9.81 \mathrm{~m} \mathrm{~s}^{-2}$. The excess fluid pressure $p_{e}$ is assumed equal to the average in situ tensile strength, $T_{0}=3 \mathrm{MPa}$ (Gudmundsson, 2011a), and to have the potential to drive the water up to the basin surface so that the pressure gradient is $\partial p_{e} / \partial D=-1000 \mathrm{~Pa} \mathrm{~m}^{-1}$. Substituting these values into Equation (1), the volumetric flow rate $Q_{D}^{s}$ in a rigid host rock is $1.4 \times 10^{-3} \mathrm{~m}^{3} \mathrm{~s}^{-1}$. Equation (2) for the volumetric flow rate $Q_{D}^{e}$ in an elastic host rock, however, with the host rock density $\rho_{r}$ taken as $2400 \mathrm{~kg} \mathrm{~m}^{-3}$, yields $2.0 \times 10^{-3} \mathrm{~m}^{3} \mathrm{~s}^{-1}$. Buoyancy thus increases the total volumetric flow rate through the fracture by a factor of more than 1.4. The most critical parameter in these calculations, however, is the fracture aperture $b$, since its cube enters Equations (1) and (2). For a fracture with an aperture $b$ of only $0.1 \mathrm{~mm}$ (one tenth of the previous example), and all other parameters as given above, $Q_{D}^{s}$ is $1.4 \times 10^{-6} \mathrm{~m}^{3} \mathrm{~s}^{-1}-$ one thousandth of that of the first example. This indicates that even few fractures with large apertures in a set consisting of tens or hundreds of fractures may completely control the fluid flow through that set.

Fluid flow in a fractured reservoir is largely, and may be almost entirely, controlled by the permeability of its fracture network (Figures 6, 7). As an extreme case, if a reservoir consists of a completely impermeable rock except for a fracture network, fluid flow could occur only along the fractures irrespective of the hydraulic gradient. No large-scale flow, however, takes place along a particular fracture network unless the fractures are interconnected.

For fluid flow to occur from one site to another there must be at least one interconnected cluster of fractures that links these sites (Figure 6). The condition that such a cluster exists is commonly referred to as the percolation threshold (Stauffer and Aharony, 1994). Fractures that are restricted to single layers (Figure 7) normally have a lower probability of being interconnected with other fractures than fractures that dissect many layers (e.g., Priest, 1992) and thus often do not contribute significantly to permeability in reservoirs. Fractures restricted to single layers are referred to as stratabound or layerbound, whereas for non-stratabound fractures, layering does not affect fracture growth (Odling et al., 1999; Gillespie et al., 2001).

\section{FLUID TRANSPORT IN FAULTS}

"Deformed fractures" in the definition of Nelson (1985) are primarily shear fractures, that is, faults. Faults have strong effects on permeability (Barton et al., 1995; Finkbeiner et al., 1997; Gudmundsson, 2000a). They can be sealing (Jones et al., 2008), but they are commonly major water conduits (Bruhn et al., 1994; Caine et al., 1996; Evans et al., 1997; Haneberg et al., 1999; 


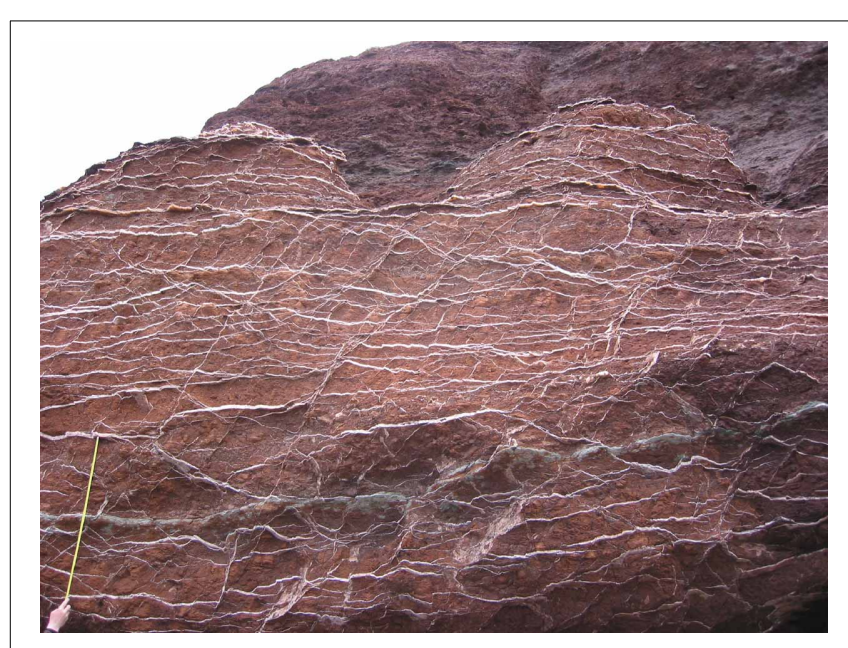

FIGURE 6 | In comparatively homogeneous rocks, such as these thick mudstones at Watchet, Somerset coast, Southwest England (cf. Philipp, 2008), there may develop interconnected networks of mineral veins (here of gypsum) or other hydrofractures. Mudstones commonly have a very low permeability, but such well-interconnected networks of hydrofractures may generate a high temporary permeability. View east; the measuring steel tape is $1 \mathrm{~m}$ long.

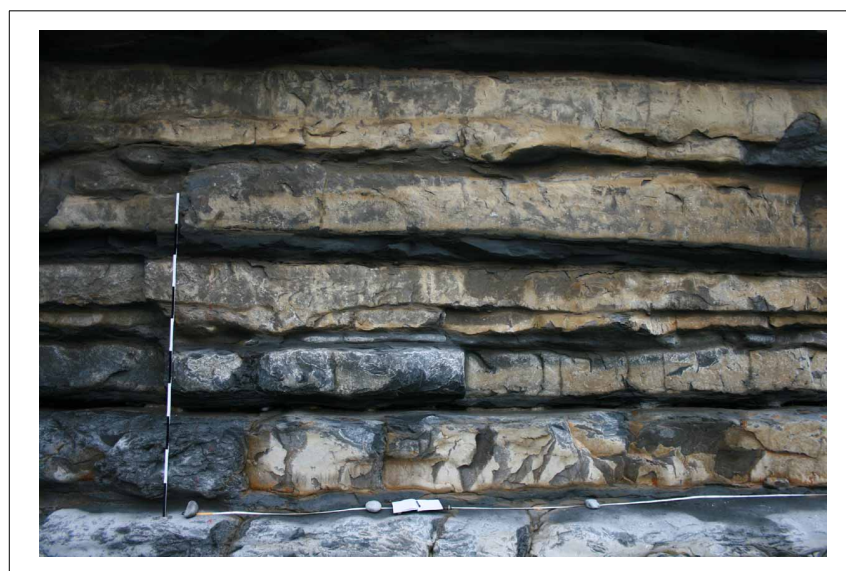

FIGURE 7 | In mechanically layered rocks, such as this succession of limestone and shale at Nash Point, Glamorgan coast, South Wales, many fractures, such as these joints, become restricted to certain layers. The joints presumably became arrested when their tips tried to propagate from the stiffer limestone layers into the much softer shale layers. Arrested fractures contribute significantly less to the overall permeability of a fluid reservoir than do fractures that propagate through many layers, since they are less likely to develop interconnected fracture systems that reach the percolation threshold. View east; the measuring steel tape is $2 \mathrm{~m}$ long. example, the effects of fault slip during earthquakes include changes in yield of springs, water table, and stream flow (Roeloffs, 1988; Muirwood and King, 1993; Rojstaczer et al., 1995; King et al., 1999; Grecksch et al., 1999). Similar effects occur in hydrothermal systems. During fault slip all the pores and small fractures that meet with the slip plane become interconnected so that the fault develops temporarily a high hydraulic conductivity (Gudmundsson, 2000a). When active, a fault plane with an aperture of less than $1 \mathrm{~mm}$ is able to transport more water than a $100 \mathrm{~m}$ thick porous layer of average hydraulic conductivity of $10^{-7} \mathrm{~m} \mathrm{~s}^{-1}$ (Lee and Farmer, 1993; Gudmundsson, 2000a).

The best evidence of former fluid transport paths, particularly in deeply eroded, inactive fault zones, are networks of mineral veins (McCaffrey et al., 1999; Gudmundsson et al., 2002). For example, in a Liassic limestone-shale succession in England, calcite veins occur almost exclusively in the damage zones and the cores of normal faults, indicating that the fault planes transported the fluids that formed the veins (Figure 8). Some veins were clearly injected into the limestone layers of the damage zone directly from the fault plane (Brenner, 2003; Brenner and Gudmundsson, 2004a; Gudmundsson et al., 2010). Many inactive faults are of low permeability and even act as seals for fluids, particularly if they develop clay smear along their planes. Fault planes in sedimentary basins, however, tend to be planes of weakness. Overpressured fluids that flow into such planes are likely to follow the fault planes to higher stratigraphic levels as hydrofractures. These hydrofractures may then be injected into the rocks in the damage zone of the fault zone and build interconnected fracture networks.

The current stress field also controls fluid flow in, and therefore the permeability of, fractured reservoirs (Heffer et al., 1997; Faybishenko et al., 2000; Gudmundsson, 2000b; Smart et al., 2001). One reason for this is that fractures are sensitive to changes in the stress field and deform much more easily than circular pores. In a fault zone where most fractures in the damage zone are subparallel to the main fault plane the effect of the current stress field on permeability can be strong. In a stress field where the maximum principal compressive stress is perpendicular to the trend of the fractures, many fractures will be closed and fluid flow inhibited. In a stress field where the maximum principal compressive is parallel with the fracture trend, however, fractures tend to be opened up and fluid transport is enhanced (e.g., Finkbeiner et al., 1997; Twiss and Moores, 2006). Another reason for the control of the current stress field on fluid transport is that faults may be more permeable when they are critically stressed that is, close to slip in an earthquake (Barton et al., 1995). A third reason is that the stress field contributes to the fluid overpressure of hydrofractures.

\section{HYDROFRACTURE EMPLACEMENT HYDROFRACTURE INITIATION}

For a hydrofracture to be able to transport fluids, the fracture must be initiated at its source and then propagate for the eventual distance of fluid transport. Fracture initiation depends on the stress conditions at the source (see below, Equation 3), whereas fracture propagation depends on the stress conditions at the fracture tip (cf. section Hydrofracture Propagation). For dykes and 


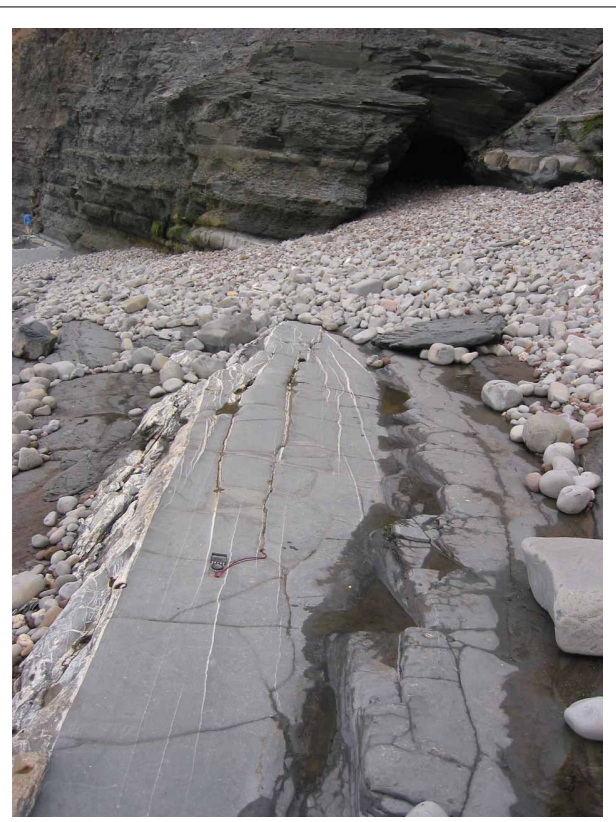

FIGURE 8 | View along strike of a normal fault at Kilve, Somerset coast, Southwest England (cf. Philipp, 2012). There is a dense network of calcite veins running subparallel to the fault plane. The veins extend for a distance of only a few meters away from the fault plane into the damage zone. For the veins in the foreground that are continuous non-restrictive, and undeformed extension fractures and for which both ends are visible in the outcrop, the outcrop length/aperture (thickness) ratios can be measured, so that the fluid overpressure at the time of hydrofracture formation (cf. Figure 9) can be estimated using Equation (5). View east; see the compass for scale.

sheets, the sources are magma chambers; for subvertical mineral veins and joints likely sources include subhorizontal water sills (Sun, 1969; Fyfe et al., 1978). Such a fluid sill does not necessarily consist only of fluids but is rather a zone of accumulation of fluids which may mainly occupy the pores, as is common in sedimentary rocks. Fluid source is here used in the sense of a fluid accumulation zone with high fluid pressure (e.g., Osborne and Swarbrick, 1997) where a hydrofracture originates.

Hydrofractures normally initiate when the total fluid pressure $p_{f}$ becomes equal to the sum of the minimum principal compressive stress $\sigma_{3}$ in the roof of the source and in situ tensile strength $T_{0}$ of the rock in the roof so that the roof ruptures in extension, namely (Gudmundsson et al., 2002):

$$
p_{f}=p_{l}+p_{e}=\sigma_{3}+T_{0}
$$

where $p_{l}$ is the lithostatic stress at the depth of the fluid source. This is equivalent to that the internal fluid excess pressure $p_{e}$ (the pressure in excess of the minimum principal compressive stress; Figure 9) reaches the local in situ tensile strength.

Excess pressure can be generated by several mechanisms. For example, artesian aquifers and petroleum reservoirs may be highly pressured due to impermeable seals and the buoyancy of the fluids (de Marsily, 1986; Chilingar et al., 2002; Deming, 2002).

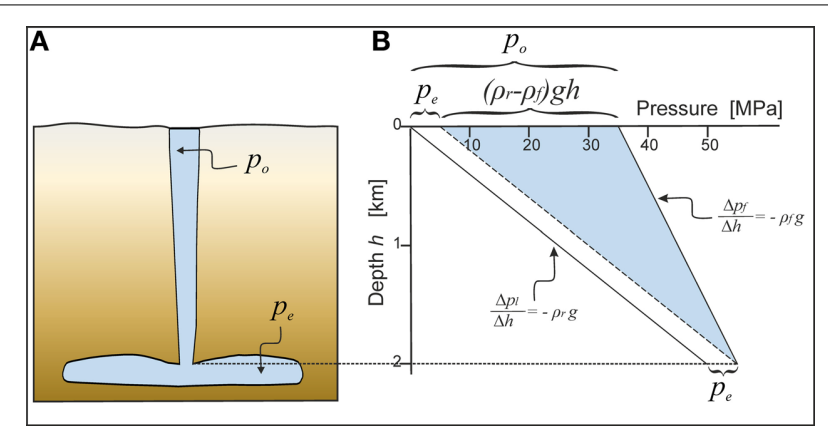

FIGURE 9 | (A) In an elastic crust (cf. Figure 5), the weight of the rock above the source is supported by the fluid pressure in the source. In the roof of the source, a lithostatic state of stress is assumed that is, $p_{l}=\sigma_{1}=\sigma_{2}=\sigma_{3}$. In the fluid source an internal fluid excess pressure $p_{e}$ may occur (in excess of the lithostatic stress), and if $p_{e}$ reaches the local in situ tensile strength $T_{0}$ of the rock in the roof, the fluid source ruptures and a hydrofracture is initiated (Equation 3 ). In the propagating hydrofracture, the fluid pressure in excess of the normal stress on the fracture plane, which for extension fractures is the minimum principal compressive stress, $\sigma_{3}$, is referred to as overpressure $p_{0}$. (B) Illustration of the buoyancy effect that leads to the fluid overpressure $p_{O}$ in the hydrofracture being different from the excess pressure $p_{e}$ because the density of the host rock, $\rho_{r}$, is different from that of the fluid, $\rho_{f}$. In the roof of the fluid source the total fluid pressure $p_{f}$ at the time of rupture is equal to the sum of the lithostatic stress $p_{l}$ and the excess pressure $p_{e}$ (Equation 3). Assuming a fluid density $\rho_{f}$ of $1000 \mathrm{~kg} \mathrm{~m}^{-3}$ (water), according to the weight gradient $\frac{\Delta p_{f}}{\Delta h}=-\rho_{f} g$ the fluid pressure inside the hydrofracture decreases upwards with roughly $10 \mathrm{MPa} \mathrm{km}{ }^{-1}$. The lithostatic stress $p_{\text {l }}$ in the host rock, however, decreases according to the equation $\frac{\Delta p_{l}}{\Delta h}=-\rho_{r} g$ and must be zero at the Earth's surface. Assuming a host rock density $\rho_{r}$ of $2500 \mathrm{~kg} \mathrm{~m}^{-3}$ (average sedimentary rock), the gradient is roughly $25 \mathrm{MPa} \mathrm{km}^{-1}$. If the fluid reservoir is located at $2 \mathrm{~km}$ depth, the lithostatic stress in the roof of the fluid source is $50 \mathrm{MPa}$, and the fluid overpressure $p_{0}$ at the surface is therefore $35 \mathrm{MPa}$. This overpressure $p_{o}$ depends on the excess pressure $p_{e}$ in the source (here assumed to be $5 \mathrm{MPa}$ ), and the buoyancy term $\left(\rho_{r}-\rho_{f}\right)$ $\mathrm{g} \mathrm{h}$. The differential stress $\sigma_{d}$ (Equation 4 ) is not illustrated here. The size of the shaded area in the diagram indicates that the buoyancy effect increases upwards, so that the hydrofracture aperture also increases upwards, as is indicated in (A).

Alternatively, tectonic stresses, such as horizontal tension parallel to the fluid reservoir, or stresses related to active faulting, may reduce one of the horizontal principal stresses leading to the rupture of the reservoir roof (cf. Gudmundsson, 2006). Also, in low-permeability rocks fluid excess pressure may build up locally during mineral transitions (Philipp, 2008).

\section{HYDROFRACTURE PROPAGATION}

Hydrofractures propagate by advancing their tips when the associated tensile stresses exceed the tensile strength of the host rock (this criterion can also be formulated using fracture toughness rather than tensile strength) (e.g., Valko and Economides, 1995). Propagating hydrofractures form their paths by gradually linking up discontinuities in the host rock ahead of their tips into which the fluids subsequently flow. A discontinuity is any significant mechanical break or fracture of low or zero tensile strength in the rock (Priest, 1992). Thus, the stress fields in combination with the discontinuities ahead of a hydrofracture tip largely determine the fracture-propagation path. Favorably oriented discontinuities 
ahead of the tip open up when they are subject to tensile stresses that exceed their tensile strengths.

Numerical models (e.g., Gudmundsson and Brenner, 2001, 2005; Brenner, 2003; Gudmundsson, 2006; Gudmundsson and Philipp, 2006) show that the maximum concentration of the maximum principal tensile stress (minimum principal compressive stress), $\sigma_{3}$, occurs at the margins of fluid reservoirs and decreases rapidly with distance from the reservoir (cf. Savin, 1961). This indicates that, commonly, the conditions of hydrofracture initiation and propagation are satisfied at the margin, and in the vicinity of, the reservoir, whereas at greater distances from the reservoir the stress conditions favor hydrofracture arrest. Consequently, the intensity of hydrofractures injected from a fluid reservoir should normally decrease away from the reservoir, the propagation direction being radially away from the reservoir, in agreement with observations of sheet and dyke swarms (Gudmundsson, 2006).

\section{FLUID OVERPRESSURE OF HYDROFRACTURES}

The term excess pressure refers to the pressure in excess of the minimum principal compressive stress $\sigma_{3}$ or, for a lithostatic state of stress, the overburden pressure in the reservoir roof. Outside the reservoir, in a propagating hydrofracture (Figure 9A), the fluid pressure in excess of the normal stress on the fracture plane, which for extension fractures is the minimum principal compressive stress, $\sigma_{3}$, is referred to as overpressure $p_{o}$. Thus, $p_{o}$ is the pressure available to drive the fracture walls open at a particular point. The term "overpressure" in the sense used here is well-established in the technical literature (Heimpel and Olson, 1994; Bonafede and Rivalta, 1999a,b). However, $p_{o}$ is also referred to as driving pressure or driving stress (Pollard and Segall, 1987; Vermilye and Scholz, 1995; Dahm et al., 2010), or as net pressure (Valko and Economides, 1995). Fluid overpressure, as defined here, is not to be confused with an abnormal pore formation pressure. Such confusion may occur because in part of the literature the hydrostatic pressure is regarded as normal, a lower formation pressure is referred to as subnormal, and a higher formation pressure as supernormal (Selley, 1998) or overpressure (Hubbert and Rubey, 1959; Chapman, 1981; Dahlberg, 1994; Chilingar et al., 2002).

In higher stratigraphic levels hydrofractures commonly develop a fluid overpressure $p_{o}$ due to the buoyancy effect if host rock and fluid have different densities (Figure 9B; Spence et al., 1987; Rubin, 1995; Ray et al., 2007; Geshi et al., 2010; Gudmundsson et al., 2012). This overpressure $p_{o}$ depends on the excess pressure $p_{e}$ in the source, the buoyancy term $\left(\rho_{r}-\rho_{f}\right)$, and the differential stress $\sigma_{d}$ (the difference between the principal stresses $\sigma_{1}-\sigma_{3}$ ) in the host rock at the depth under consideration (for example, an exposure of a mineral vein), thus:

$$
p_{o}=p_{e}+\left(\rho_{r}-\rho_{f}\right) g h+\sigma_{d},
$$

where $h$ is the height of the hydrofracture above the fluid source (Figure 5) and the other parameters are as defined in Equations (1-3). For water in a sedimentary basin, the buoyancy term $\left(\rho_{r}-\rho_{f}\right)$ is always positive and $h$ is zero in the roof of the fluid source and increases upwards that is, on approaching the Earth's surface. It follows, since both $\left(\rho_{r}-\rho_{f}\right)$ and $h$ are positive that the buoyance increases upwards that is toward the Earth's surface. Consequently, the overpressure $p_{o}$ in a hydrofracture increases upwards away from the reservoir and reaches its maximum value at the surface (Figure 9B). For magma in a dyke, the buoyancy term may become negative when the dyke propagated through low-density rocks, so that the overpressure may approach zero, but for water the buoyancy effect and the overpressure always increase right up to the surface.

The fluid overpressure at the time of formation of paleohydrofractures, such as mineral veins and dykes, can be estimated using physical principles that relate fluid pressures to the fracture aspect (length/aperture) ratios. A subvertical hydrofracture extending from a fluid reservoir to an open contact between layers (or to the surface) can be modeled as a through crack (Figure 3). The fracture height can then be considered infinite and thus the outcrop length is the shorter, controlling, dimension. For a fluidfilled extension fracture modeled as a through crack with outcrop length $L$ and maximum aperture $b_{\max }$, the static overpressure $p_{o}$ is given by (Sneddon and Lowengrub, 1969; Gudmundsson, 2000b):

$$
p_{o}=\frac{b_{\max } E}{2 L\left(1-v^{2}\right)}
$$

where $E$ is Young's modulus and $\nu$ Poisson's ratio of the host rock.

Rearranging Equation (4), the fluid overpressure calculated from Equation (5) can be used to estimate the height of the hydrofracture that is, the depth $h$ to the fluid source below the present outcrop (Figure 9; Gudmundsson, 1999):

$$
h=\frac{p_{o}-\left(p_{e}+\sigma_{d}\right)}{\left(\rho_{r}-\rho_{f}\right) g}
$$

where all the parameters are as defined above (cf. Becerril et al., 2013).

As an example, we use these analytical models to estimate the fluid overpressure at the time of vein formation for 239 calcite veins in Liassic limestone layers associated with normal faults in England (Figure 8). The outcrop length $L$ and aperture $b$ of these veins have a reasonable linear correlation with an aspect (length/aperture) ratio of 451 (Philipp, 2012). First, however, the mechanical properties of limestone at the time (presumably Cretaceous) and depth $(\sim 1-2 \mathrm{~km})$ of vein formation have to be estimated. Because the limestones were young at the time of vein formation and in situ values are normally lower than laboratory values, Young's modulus is likely to have been in the lower range of typical laboratory values for limestone (10-80 GPa; Bell, 2000); $E=15 \mathrm{GPa}$ is a reasonable value. Using 0.25 for Poisson's ratio, a common value for limestones (Jumikis, 1979; Bell, 2000; Gudmundsson, 2011a), Equation (5) gives the average fluid overpressure $p_{o}$ as $18 \mathrm{MPa}$ (cf. Philipp, 2012).

In Equation (6) we use the limestone density of $2400 \mathrm{~kg} \mathrm{~m}^{-3}$ (Bell, 2000) for $\rho_{r}$ and the water density (for water at $90^{\circ} \mathrm{C}$ ) of $965 \mathrm{~kg} \mathrm{~m}^{-3}$ (Smits, 2000) for $\rho_{f} . p_{e}$ is equal to local in situ tensile strength $T_{0}$ (Equation 3 ) and $\sigma_{d}$ normally cannot be greater than $4 T_{0}$ (Gudmundsson et al., 2002). Common in situ tensile strengths $T_{0}$ of solid rocks are $0.5-6 \mathrm{MPa}$, most frequently 2-3 MPa (Haimson and Rummel, 1982; Schultz, 1995; Amadei 
and Stephansson, 1997). Using these values, Equation (6) gives the depth of the water source from 213 to $568 \mathrm{~m}$. Using extreme variations of all the included parameters yields a maximum depth of $1200 \mathrm{~m}$ (cf. Philipp, 2012) which is in agreement with oxygen and carbon isotope data indicating fluid sources of the veins 20$30^{\circ}$ hotter than the host rocks (Davison, 1995). For 384 quartz veins in basalt in a fault zone in North Iceland, the average aspect ratio is 400 ; the average overpressure is then estimated at $20 \mathrm{MPa}$ and the depth calculated as being in a similar range as for the example from England (Gudmundsson et al., 2002). This indicates that in both cases, the geothermal water that formed these veins accumulated in sources at shallow depths and was thus of a rather local origin.

\section{HYDROFRACTURE TIP STRESSES}

To calculate the tip stresses of a rock fracture in general, and a hydrofracture in particular, two approaches have normally been used (Jaeger and Cook, 1979). One is to use a mathematical crack of zero thickness, an approach frequently used in fracture mechanics (Figure 10A; Sneddon and Lowengrub, 1969; Maugis, 2000). The other principal approach in modeling rock fractures is to consider the crack as a flat elliptical hole (Figure 10B; Savin, 1961; Maugis, 2000). This approach is more common in rock mechanics.

A mathematical crack (Figure 10A) is an appropriate model for many hydrofractures, particularly those that initiate as narrow cracks with very thin, hair-like tips; for example many joints (cf. Kusumoto et al., 2013a,b). A hydrofracture located on the vertical $y$-axis is defined by $x=0,-a \leq y \leq a$. The internal fluid overpressure (also referred to as driving pressure or net pressure) of the hydrofracture is given by the even function $p(x)=p(-x)$, so that the pressure is the same on the walls to the left and to the right of the vertical $y$-axis. For a constant overpressure $p(x)=-p_{o}$, so that inside the fracture, for $0 \leq y \leq a, \sigma_{3}=p_{0}$. Beyond the fracture tips, for $y>a$, the crack-tip tensile stress $\sigma_{3}(y, 0)$ is (Maugis, 2000):

$$
\sigma_{3}=-p_{0} y\left[\frac{1}{\left(y^{2}-a^{2}\right)^{1 / 2}}-\frac{1}{y}\right]
$$

This indicates that when the hydrofracture tip is approached from outside, $y \rightarrow a$, the principal stress $\sigma_{3}$ becomes infinite. Similar solutions are obtained if the overpressure is not constant but varies linearly or by another mathematical law. In nature, however, a crack-tip process or damage zone, plastic flow and, for hydrofractures, a near-tip underpressured zone make the tip stresses finite (Valko and Economides, 1995).

The elliptical hole with a major axis $2 a$ and a minor axis $2 c$ (so that $2 c=b$ is its aperture; Figure 10B) is an appropriate model for many types of fractures. As regards fracture morphology, these include many open fractures, mineral veins, and vuggy fractures. In addition, an elliptical hole is often a reasonable model for some tension fractures in rift zones, as well as for many hydrofractures such as dykes, sills, and inclined sheets (e.g., Gudmundsson, $2000 \mathrm{~b}$ ). The minimum principal stress $\sigma_{3}$ at the tips of an elliptical hole subject to a fluid overpressure $p_{o}$ is (Peterson, 1974; Maugis, 2000):

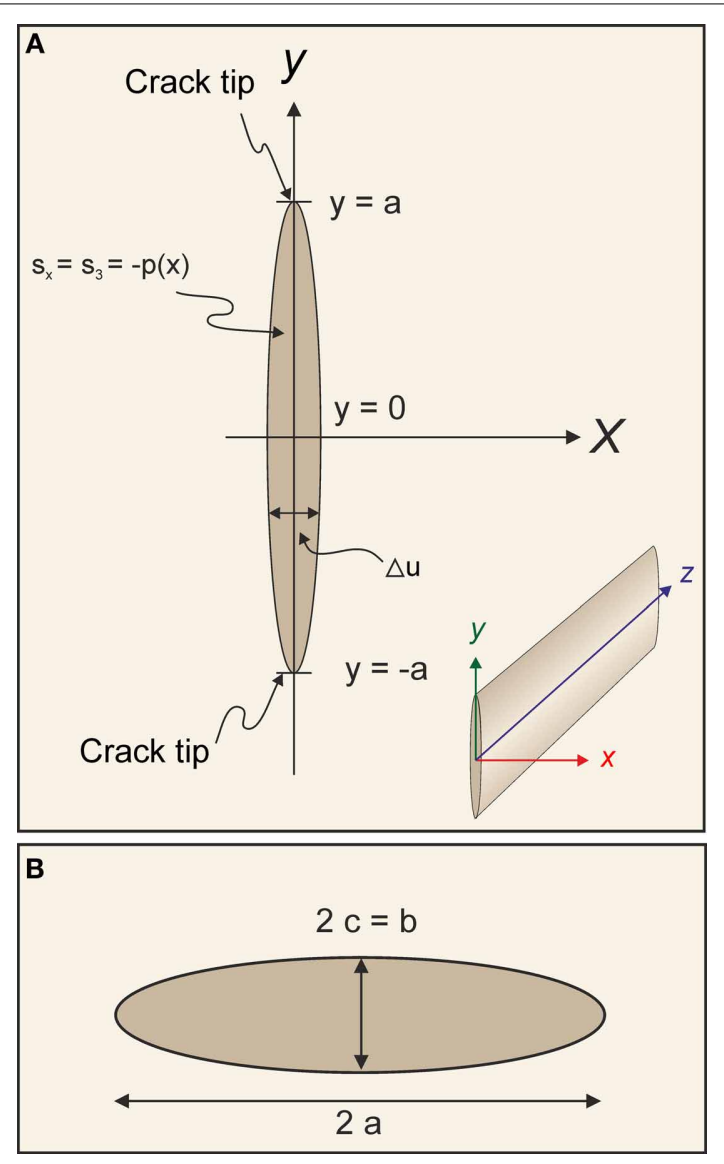

FIGURE 10 | (A) Schematic illustration of a mathematical crack as a fracture representation. The crack has a length $2 a$ along the $y$-axis and its opening displacement $\Delta u$ depends on the fluid overpressure inside the fracture. At the crack tips, the crack-tip tensile stresses become infinite (Equation 7). (B) Schematic sketch of an elliptical hole with a minor axis $2 c=b$ and a major axis 2a. The crack-tip tensile stress is calculated with Equation (8).

$$
\sigma_{3}=-p_{o}\left[\frac{2 a}{c}-1\right]
$$

As an example, we calculate the tip tensile stresses for the calcite veins presented above (section Fluid Overpressure of Hydrofractures). With an aspect ratio $a / c=451$ and an estimated fluid overpressure of $p_{o}=18 \mathrm{MPa}$, Equation (8) yields an average crack-tip tensile stress of $\sim 1.6 \times 10^{4} \mathrm{MPa}$. Using common aspect ratios of regional dykes, measured in lateral sections in Iceland, as 900-1000, and their estimated overpressures as several tens of mega-pascals (Gudmundsson, 2006), we obtain $\sigma_{3}$ at a lateral dyke tip as $\sim 10^{4} \mathrm{MPa}$, the same order of magnitude as for the mineral veins.

To explore stress fields affecting hydrofracture propagation we have run many numerical models (cf. e.g., Gudmundsson and Brenner, 2001, 2005; Brenner and Gudmundsson, 2002, 2004a,b; Gudmundsson and Philipp, 2006). Here we present boundaryelement models (Brebbia and Dominguez, 1992) using the program BEASY (www.beasy.com) that are similar to previously 
published models to illustrate and explain better the results presented here. As for many three-dimensional problems, one dimension can be considered as effectively infinite so that the problem can be modeled in two dimensions, using specific equations for the condition referred to as plane strain (one principal strain is zero; Jaeger and Cook, 1979). All models are scaleindependent so that the results can be used for any size of hydrofracture.

First we explore the tensile stress at a hydrofracture tip in a homogeneous, isotropic rock (Figure 11), where a hydrofracture subject to a constant fluid overpressure of $10 \mathrm{MPa}$ is located in a crust with Young's modulus $100 \mathrm{GPa}$ and Poisson's ratio of 0.25 . The model is three units high and six units wide. The units used here are arbitrary measures of distance and primarily to indicate the aspect (height/width) ratio of the model and the related size and depth of the hydrofracture. In the

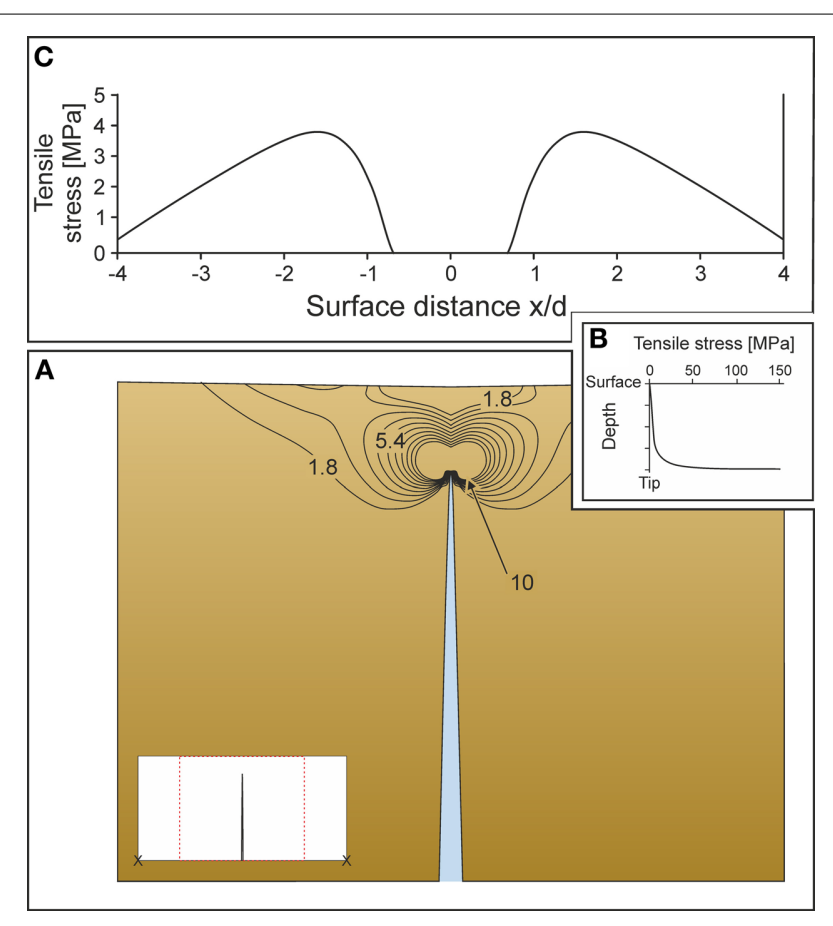

FIGURE 11 | Boundary-element model of the tensile stress around a hydrofracture in a homogeneous isotropic crust with Young's modulus $\mathbf{1 0 0 ~ G P a}$, Poisson's ratio $\mathbf{0 . 2 5}$. The inset in (A) shows the set-up of the model: the model is 3 units high and 6 units wide. The dashed lines indicate the part of the model which is shown on the large results figure. The crosses indicate the boundary conditions of no displacement in the lower corners of the model. The hydrofracture tip is at 0.5 units below the surface. (A) Concentration of the maximum principal tensile stress (minimum compressive stress) $\sigma_{3}$, in mega-pascals (truncated at 1 and $10 \mathrm{MPa}$ ). The aperture of the hydrofracture is shown 150 times exaggerated. In a large area around the fracture tip, tensile stresses exceed $10 \mathrm{MPa}$. (B) Tensile stress distribution from the surface to the hydrofracture tip. The tensile stress is zero at the surface, but at the tip, it reaches $149 \mathrm{MPa}$. (C) Maximum principal tensile stress at the surface. The tensile stress distribution has a peak of $4 \mathrm{MPa}$ on either side of the fracture tip at a horizontal distance 1.6 times the distance to the hydrofracture tip below the surface ("surface distance"). model, the hydrofracture tip is at 0.5 units below the surface so that the fracture half-length $a$ is 2.5 units; the initial (undeformed) thickness $b$ of the hydrofracture is 0.04 units. This fracture has the shape of a rhombus, not of an ellipse, so that Equation (8) cannot be used to obtain its tip stress. In nature, the dip dimension (height) of such a hydrofracture could be in the order of tens or hundreds of meters. Since fluid overpressure is the total fluid pressure minus the stress normal to the fracture, remote tension, or compression (e.g., due to gravity) is automatically included in the loading conditions for the layer hosting the fracture (Gudmundsson et al., 2012; Kusumoto et al., 2013a,b). To avoid rigid body translation and rotation, the model needs to be fastened (using the condition of no displacement). In order to allow the hydrofracture to deform freely, however, the model is fastened in the lower corners only.

The magnitude of the tensile stress around the hydrofracture tip is shown in Figure 11A as contours of the minimum principal compressive (maximum principal tensile) stress $\sigma_{3}$ in mega-pascals (MPa; truncated at 1 and $10 \mathrm{MPa}$ ). The maximum calculated tensile stress at the fracture tip is $149 \mathrm{MPa}$ (Figure 11B), and there is a large area around the fracture tip where the tensile stress exceeds $10 \mathrm{MPa}$ (Figure 11A). The tensile stress then falls off quickly with distance from the fracture tip (Figure 11B). At the surface directly above the fracture tip, no tensile stresses occur, but the tensile stress concentration at the surface has two peaks (Figure 11C). This is similar to analytical solutions for vertical extension fractures in a homogeneous, isotropic elastic half space subject to remote tensile stresses, or internal fluid pressure (Isida, 1955).

Since the in situ tensile strength of common solid rocks varies from 0.5 to $6 \mathrm{MPa}$ (Haimson and Rummel, 1982; Schultz, 1995; Amadei and Stephansson, 1997), the above results from analytical and numerical models indicate that theoretical tip tensile stresses are from one hundred to ten thousand times greater than the tensile strength of the host rock through which these hydrofractures propagate. Similar results follow from other models of hydrofractures in homogeneous, isotropic rocks (Weertman, 1971; Secor and Pollard, 1975). This indicates that, for a homogeneous and isotropic rock, any significant overpressure in a hydrofracture normally generates very high (and for a mathematical crack, infinite) crack-tip tensile stresses so that any continuous and buoyant hydrofracture should propagate to the earth's surface.

Natural rocks, however, are normally heterogeneous and anisotropic and most hydrofractures become arrested at various crustal depths. In mechanically layered rocks, in particular, arrested hydrofractures are common. This is evidenced by many field observations of dykes, veins, and joints and field and laboratory experiments on man-made hydraulic fractures in petroleum engineering. Layering in solid materials in general is known to have strong effects on fracture propagation (e.g., Daniel and Ishai, 1994; Broberg, 1999; Brooks and Choudhury, 2002; Nasseri et al., 2006; Zhang et al., 2007; Tvergaard and Hutchinson, 2008). In the following section we explore hydrofracture emplacement in mechanically layered rocks in detail. 


\section{HYDROFRACTURE EMPLACEMENT IN MECHANICALLY LAYERED ROCKS \\ MECHANICAL LAYERING OF RESERVOIR ROCKS}

Layering is a common feature of many heterogeneous rock masses. Layered reservoirs are well-known in the field of petroleum engineering (Aguilera, 2000; Economides and Boney, 2000). In that field, a practical distinction is often made between laminated and layered reservoirs in that a reservoir is referred to as layered when the layers are thick enough to be targeted by a horizontal well, but as laminated when the layers are too thin for such a targeting to be possible (Economides and Boney, 2000). Generally, laminated reservoirs have a poor vertical permeability (Economides and Boney, 2000). In layered reservoirs, the permeability from layer to layer can vary considerably. Generally, ignoring the variation in permeability between layers in a reservoir can lead to an overestimate of its overall permeability (Aguilera, 2000).

One main reason why the permeability may vary considerably between rock layers is that some layers host more interconnected fractures than others. In turn, the fracture frequency in a single layer depends on the chances of fracture development in that layer. Since fracture development is mostly controlled by the state of stress in the host rock (Warpinski et al., 1982) which in turn correlates with rock mechanical properties (Hudson and Harrison, 1997), fracture development is largely controlled by the mechanical properties of the layers. In order to understand fracture development in layers that themselves are homogeneous and isotropic (even if the rock as a whole is heterogeneous and anisotropic), at least two elastic constants must be determined. The two constants most commonly used in rock mechanics are Young's modulus and Poisson's ratio (Hudson and Harrison, 1997).

At low temperatures and pressures and up to about $1 \%$ strain, most solid rocks behave approximately as linear elastic materials (Paterson, 1978; Farmer, 1983). This means that Hooke's law (strain varies linearly with stress) is approximately valid and Young's modulus $E$ of that rock can be defined as the ratio of stress to strain. Young's modulus is a measure of the stiffness of the rock and is often referred to as stiffness. Following the tradition in engineering rock mechanics, layers with high Young's moduli are referred to as stiff and those with low Young's moduli as soft. As measured in the laboratory, Young's moduli for common bedrocks range from less than $0.1 \mathrm{GPa}$ for some soft sediments and pyroclastic rocks to as much as $130 \mathrm{GPa}$ for some igneous and metamorphic rocks, with the most common values being 1100 GPa (Hatheway and Kiersch, 1982; Afrouz, 1992; Bell, 2000; Schön, 2004; Gudmundsson, 2011a).

Because hydrofracture propagation is normally slow compared with the velocity of seismic waves (Valko and Economides, 1995), it is appropriate to use static Young's moduli, normally 2-10 times lower than the dynamic moduli (Goodman, 1989), for analyses of hydrofractures. Also, in situ elastic properties are normally different from those measured in the laboratory. In particular, in situ static Young's moduli tend to be as much as 1.5-5 times lower than that measured of the same rock type in the laboratory (Heuze, 1980). This is mainly because fractures in in-situ rock masses lower their stiffnesses whereas the rock samples measured in the laboratory are essentially free of fractures (Goodman, 1989; Priest, 1992; Hudson and Harrison, 1997). With increasing pressure and temperature, and thus with increasing depth in the crust, however, the differences between the laboratory and in situ values decrease.

Poisson's ratio $v$ is a measure of the absolute ratio of strain in perpendicular directions. The range of Poisson's ratios for bedrocks is, as compared with Young's modulus, narrow. Typical values for solid rocks range from 0.2 to 0.35 with $\nu=0.25$ being most common (Jaeger and Cook, 1979; Jumikis, 1979; Bell, 2000).

Rock masses where the mechanical properties change between layers are commonly referred to as mechanically layered. Mechanical layering may coincide with changes in grain size, mineral content, or facies. For example, in layered sedimentary reservoirs, such are common in carbonates (limestone interlayered with marl) or siliciclastics (sandstone interlayered with shale or clay), some rock types forming individual layers (such as limestone or sandstone) may be considerably stiffer than other layers (such as marl or clay) (Bell, 2000; Schön, 2004; Gudmundsson, 2011a). Also volcanic rocks are commonly mechanically layered, since they often consist of rather stiff lava flows (and sills) and softer volcanic tuffs or other pyroclastic rocks (Bell, 2000). In metamorphic rocks mechanical layering can be observed, for example, in many gneisses where leucosome and melanosome may have different mechanical properties (Hatheway and Kiersch, 1982). However, if a layered rock mass has essentially the same Young's modulus throughout, and if the layers are welded together so that there are no weak or open contacts, the layers may function mechanically as a single layer.

\section{FIELD OBSERVATIONS AND NUMERICAL MODEL ON HYDROFRACTURE EMPLACEMENT}

In mechanically layered rocks, the mechanical properties, particularly the Young's moduli, change between layers. In many layered rocks, predominantly in sedimentary and volcanic rocks at shallow depths, the contacts between individual layers are weak (non-welded, the tensile strength across the contact being negligible) or open (cf. Gudmundsson et al., 2002; Gudmundsson, 2006). Some fractures propagate through contacts as collinear fractures (Becker and Gross, 1996), but when a propagating hydrofracture meets with a weak or open contact, such as bedding, or a layer of contrasting mechanical properties, it commonly becomes either arrested (Figure 12) or offset when it continues with a step-over upwards (Figure 13).

There are four main mechanisms by which hydrofractures become arrested, or offset: (i) material toughness, (ii) discontinuities, (iii) stress barriers, and (iv) changes in rock stiffness (Young's modulus). Since the material toughness mechanism also involves changes in stiffness across a discontinuity (e.g., a contact), mechanisms (i) and (iv) are commonly discussed together and regarded as one. All these mechanisms related to rock layering and discontinuities and all may operate together in a single rock mass during fracture propagation.

Material toughness is a well-known concept in materials science (He and Hutchinson, 1989; Kim et al., 2006; Lee et al., 2007). It is the critical strain energy release rate of a layer or the contact between layers. More specifically, material toughness, 

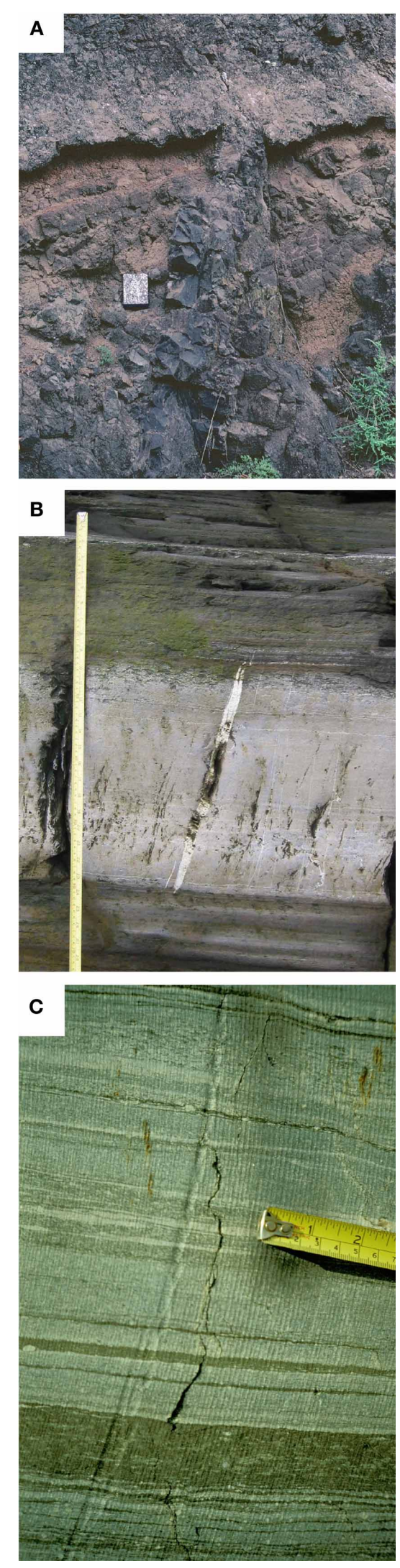

FIGURE $12 \mid$ Continued
FIGURE 12 | Arrested hydrofractures in layered rocks (cf. Brenner, 2003). (A) Arrested, blunt dyke tip in a vertical section at a road cut in Tenerife, at the contact between a pyroclastic rock layer below and a basaltic lava flow above. View west; the notebook provides a scale. (B) Arrested calcite vein at Kilve, Somerset coast, Southwest England. The vein is arrested at the contacts of a limestone layer to shale layers above and below. View east-southeast; the visible part of the measuring steel tape is $0.5 \mathrm{~m}$ long. (C) Arrested open joint in gneiss at a road cut in the city of Bergen, West Norway. The joint is arrested at the contact of leucosome layers to an amphibolitic melanosome layer. View north-northeast; visible part of the measuring steel tape is $0.065 \mathrm{~m}$ long.

denoted by $G$ and with the units of $\mathrm{J} \mathrm{m}^{-2}$, is a measure of the energy absorbed in a material (here rock) per unit area of a fracture in the material (e.g., Broberg, 1999; Gudmundsson, 2011a). The greater the material toughness of a layered rock mass then, other things being equal, the greater is the (elastic) energy needed to propagate a fracture through that mass. Analytical solutions indicate that the probability of fracture becoming deflected and/or arrested at an interface (e.g., a contact), rather than penetrating the interface, depend on the difference in Young's modulus between the layers on the opposite sides of an interface/discontinuity (e.g., a contact) and the difference in material toughness between the interface itself and the layer on the opposite side (the layer not hosting the fracture) in relation to the energy release rates associated with fracture deflection and penetration. More specifically, if there is no Young's modulus (stiffness) mismatch (no difference in Young's modulus) across the interface, then fracture deflection occurs only if contact toughness is about $25 \%$ of the toughness of the material (here the rock) on the other side of the contact (He and Hutchinson, 1989; Hutchinson and Suo, 1992; Kim et al., 2006; Lee et al., 2007; cf. Gudmundsson et al., 2010; Gudmundsson, 2011a,b). However, when the Young's modulus mismatch increases, deflection will still occur even if the material toughness of the interface/contact becomes equal to or higher than the bulk material toughness.

The term "discontinuity" includes fractures as well as contacts. A "stress barrier" for a vertical hydrofracture is a layer or discontinuity where the hydrofracture-normal compressive stress is higher than in the adjacent layers; in general, a stress barrier is any layer or contact with unfavorable stress conditions for the propagation of a particular type of a fracture. Stress barriers are particularly common in mechanically layered rocks (Haimson and Rummel, 1982; Amadei and Stephansson, 1997; Zang and Stephansson, 2010). Discontinuities, stress barriers, and changes in rock stiffness are related in that changes in stiffness and stress barriers are common at contacts (discontinuities) between different rock types (Gudmundsson and Brenner, 2001; Brenner, 2003).

An open or weak contact may open up as a fracture tip approaches it, in which case the hydrofracture normally propagates along part of the open contact or becomes arrested. A resulting deflected or T-shaped fracture is commonly observed (or inferred) in fracture mechanics (Cook and Gordon, 1964; Atkins and Mai, 1985; He and Hutchinson, 1989), in petroleum engineering hydraulic fracture studies (Gulrajani and Nolte, 2000; 

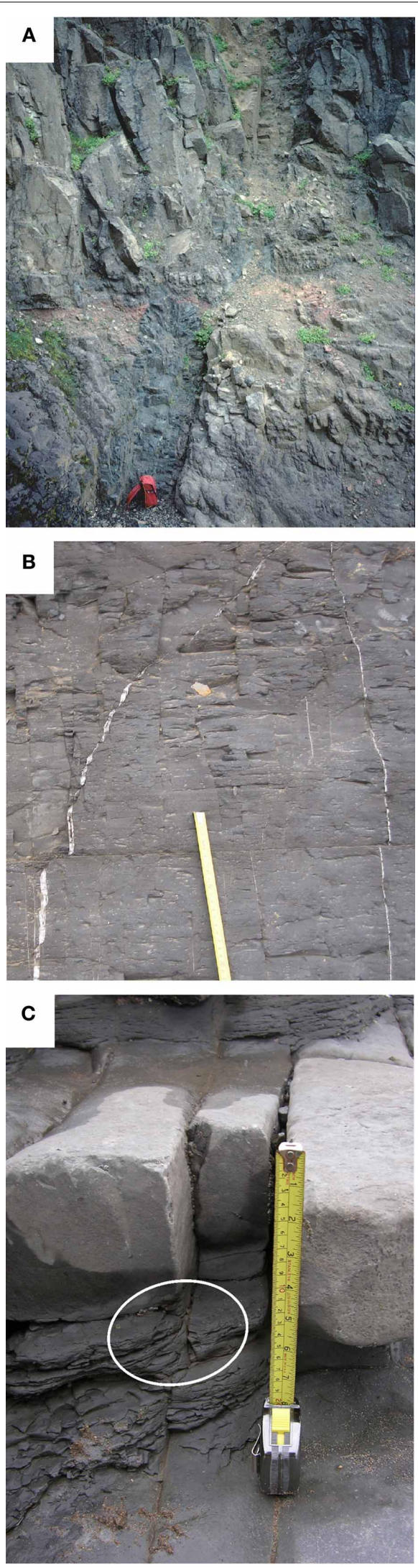

FIGURE 13 | Continued
FIGURE 13 | Hydrofractures offset at contacts (cf. Brenner, 2003). (A) Dyke becomes offset on crossing a weak scoria contact between two basaltic lava flows in the paleorift zone of North Iceland. View north; the backpack at the lower dyke segment provides a scale. (B) Calcite veins offset at a weak contact between shale layers at Kilve, Somerset coast, Southwest England. View south; the visible part of the measuring steel tape is $0.3 \mathrm{~m}$ long. (C) Joint (encircled) becomes offset at a weak contact between shale layers at Nash Point, Glamorgan coast, South Wales. View south; the measuring steel tape is $0.2 \mathrm{~m}$ long.

Kim et al., 2006; Zhang et al., 2007), and in volcanic regions where dykes change into sills (Gudmundsson, 2011b). Some fractures are also arrested by slip at contacts (interfaces). There is some field evidence for slickensides along bedding planes in sedimentary rocks (Renshaw and Pollard, 1994), and Cooke and Underwood (2001) propose that when slip occurs, crack-tip tensile stresses cannot be transmitted across the interface so that the tip becomes arrested.

Dykes often end at layer contacts which show no evidence of slip (Gudmundsson, 2006; Gudmundsson and Philipp, 2006). Many dykes, for example in Tenerife (Canary Islands) and Iceland, are arrested at contacts between lava flows and pyroclastic layers (Figure 12A; cf. Gudmundsson and Brenner, 2001; Gudmundsson and Philipp, 2006) or at bedding contacts in sedimentary rocks (Baer, 1991). Some dykes thin gradually toward the discontinuity; others end bluntly (Figure 12A). When there are stress barriers, dykes may end vertically by tapering away in relatively homogeneous and isotropic rock layers (Gudmundsson and Brenner, 2001; Gudmundsson and Philipp, 2006).

Mineral veins may also become arrested at contacts in mechanically layered rocks. For example, in layered carbonate rocks (Gillespie et al., 2001; Gudmundsson and Brenner, 2001; Brenner and Gudmundsson, 2004a,b), most of the calcite veins are confined to limestone layers and end abruptly, some with blunt tips, at the contacts to shale layers (Figure 12B).

Commonly joints, many of which are hydrofractures, terminate abruptly on meeting with contacts between layers with contrasting mechanical properties. For example, many joints in layered carbonate rocks are restricted to limestone layers (Gillespie et al., 2001; Brenner and Gudmundsson, 2004a,b; Larsen et al., 2008). Field observations show that there is often no slip at bedding contacts associated with the arrested veins and joints (Brenner and Gudmundsson, 2004a,b; Larsen et al., 2008). Also in gneiss, joints can become arrested at the contact of leucosome layers to melanosome layers (Figure 12C; Brenner and Gudmundsson, 2002).

Hydraulic fractures in petroleum engineering become arrested when their vertical tips enter layers of high fracture-perpendicular compressive stresses or meet with sharp contacts between mechanically contrasting layers (e.g., Daneshy, 1978; Simonson et al., 1978; van Eekelen, 1982; Warpinski et al., 1982; Teufel and Clark, 1984; Warpinski and Teufel, 1987; Naceur and Touboul, 1990; Valko and Economides, 1995; Charlez, 1997; Yew, 1997; Economides and Nolte, 2000; Zhang et al., 2007).

Offset of hydrofractures is also commonly observed in mechanically layered rocks, particularly when there are weak 
contacts. Lateral dyke offsets across contacts between layers of contrasting mechanical properties, such as lava flows and pyroclastic rocks (Figure 13A), are very common. In some cases, the individual arrested segments of a dyke are connected by thin, igneous veins across the contacts or the dyke may even follow the contact as a sill before it continues propagating upwards (Gudmundsson and Brenner, 2005; Gudmundsson and Philipp, 2006). However, particularly in lateral sections, many dyke segments have no visible connections, that is, the individual segments may look like individual, non-connected fractures in a section, although all dyke segments must be fed by and be connected to a magma chamber (Figure 13A). Also, mineral veins and joints may become offset along contacts. For example, some calcite veins in marly shale layers are offset (with very thin connections between the segments) at bedding contacts (Figure 13B). Similar offsets can be observed for many joints (Figure 13C; Helgeson and Aydin, 1991; Cooke and Underwood, 2001; Rijken and Cooke, 2001; Larsen et al., 2008).

These and other field observations indicate that the arrest or, more generally, offset of hydrofractures at contacts in mechanically layered rocks is very common. One reason why the mechanical properties of rock layers and contacts have such great effects on the propagation and emplacement of hydrofractures is that these mechanical conditions affect the local stress fields in rocks. From Hooke's law (strain varies linearly with stress) it follows that, for a given strain, the stress concentration in a stiff (high Young's modulus) material will be greater than in a soft (low Young's modulus) material. The local stress fields in a rock consisting of stiff and soft layers will thus be very different from the ones in homogenous, isotropic media. A weak contact (or other discontinuity) behaves as a fracture that concentrates and redistributes the local stresses and may contribute to fracture arrest (Warpinski and Teufel, 1987; Weertman, 1996; Gudmundsson and Brenner, 2001; Gudmundsson, 2011a).

Thus the local stress field associated with mechanically layered rocks largely controls whether a hydrofracture meeting a contact between rock layers of contrasting mechanical properties propagates through the contact (with or without an offset) or, alternatively, becomes arrested (Gudmundsson and Brenner, 2005; Zhang et al., 2007). The effects of discontinuities (e.g., Cook and Gordon, 1964; Daneshy, 1978; Cooke and Underwood, 2001) and stress barriers (e.g., Valko and Economides, 1995; Charlez, 1997; Yew, 1997; Smith and Shlyapobersky, 2000) on hydrofracture arrest have received more attention than have changes in rock stiffness.

With a numerical model we explore the stress field around a hydrofracture tip in a mechanically layered crust (Figure 14). A small inset in the illustration indicates the initial, undeformed geometry of the model. The model is similar to the model in Figure 11 but the crust consists here of 17 layers. The lowermost layer $\mathrm{C}$ has a thickness of 1 unit and a moderate stiffness (Young's modulus $E$ of $10 \mathrm{GPa})$. Layers A are 0.2 units thick $(E=$ $100 \mathrm{GPa})$, layers B $0.05(E=1 \mathrm{GPa})$. The layer contacts are as welded together. The hydrofracture is confined to the lowermost layer $\mathrm{C}$ and subject to a constant overpressure of $10 \mathrm{MPa}$.

The hydrofracture tip at the contact with the lowermost soft layer B becomes rounded and relatively blunt (Figure 14A). The

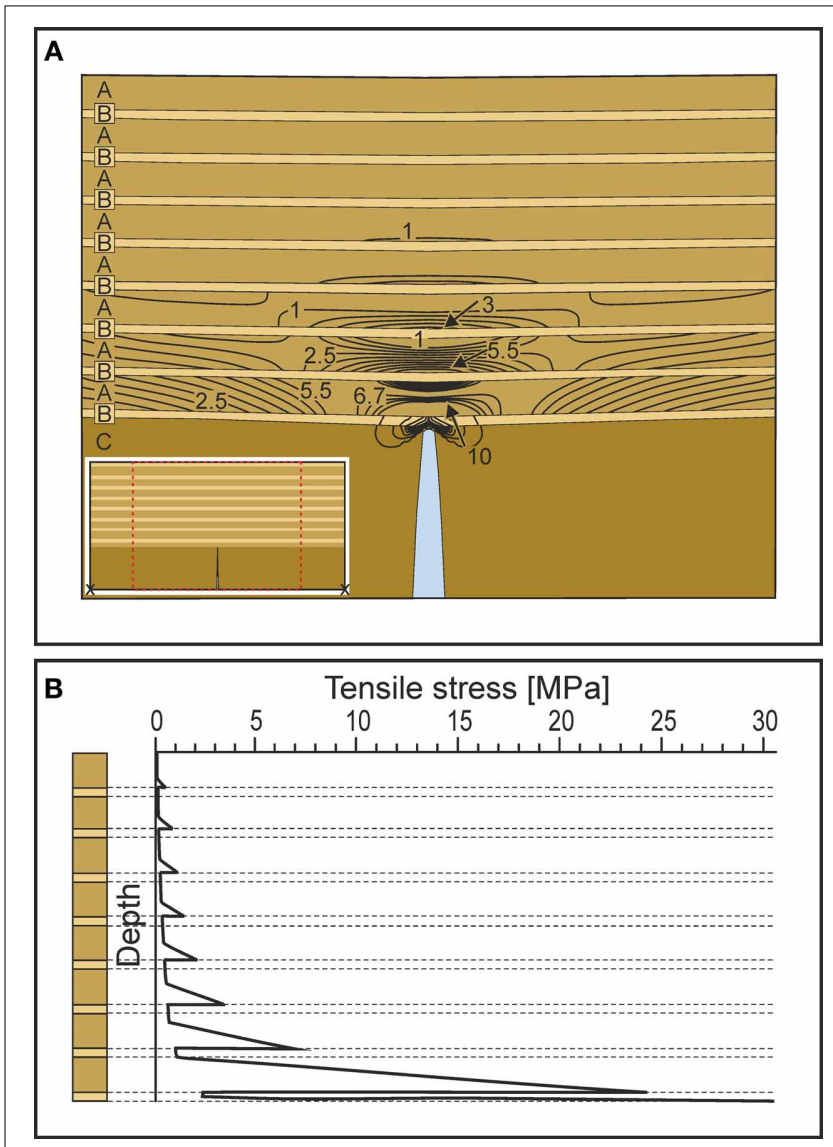

FIGURE 14 | Boundary-element model of the tensile stress around a hydrofracture in a mechanically layered crust. The inset in (A) shows the set-up of the model (cf. Figure 11): the hydrofracture tip is at 2 units below the surface. In this model, the crossed layers $A$ (thickness 0.2 units) are stiff, Young's modulus E $100 \mathrm{GPa}$, the dotted layers B (thickness 0.05 units) are very soft, $E=1 \mathrm{GPa}$; in layer $C$ Young's modulus is $40 \mathrm{GPa}$. Poisson's ratio is 0.25 in all the layers. (A) Concentration of the maximum principal tensile stress $\sigma_{3}$, in mega-pascals (truncated at 1 and $10 \mathrm{MPa}$ ). The aperture of the hydrofracture is shown 150 times exaggerated and is largest in the soft layers. As the hydrofracture tip meets with the bottom of a soft layer, it becomes wide and blunt. There is high tensile stress concentration in the stiff layer above that could induce new fractures. However, only in a small area in the soft layer next to the hydrofracture, the tensile stress exceeds $10 \mathrm{MPa}$. (B) Tensile stress distribution from the surface to the hydrofracture tip. Apart from the general increase of the tensile stress from zero at the surface to the tip, the tensile stress increases in the lower parts of all the stiff layers and is relatively lowest in all the soft layers with abrupt changes at the contacts between stiff and soft layers. The highest tensile stress, $30 \mathrm{MPa}$ occurs at the fracture tip, but this value is much lower than the tip stress for the homogeneous model (Figure 11B).

stiff layers A take up much tensile stresses, particularly in their lower parts, so that new fractures could be induced in those parts. The soft layers B, however, suppress tensile stresses. The theoretical calculated tensile stress at the fracture tip in the soft layer is $30 \mathrm{MPa}$ (Figure 14B), much lower than the tip stress of $149 \mathrm{MPa}$ for the homogeneous model above (Figure 11B). In the soft layer next to the hydrofracture tip, tensile stresses exceed common in situ tensile strengths of rocks (0.5-6 MPa; Haimson and Rummel, 
1982; Schultz, 1995) only in a very small area. It is unlikely that the hydrofracture propagates through the soft layer unless the layer contains a suitable nearby subvertical discontinuity.

\section{DISCUSSION}

In the numerical model above the contacts between layers of contrasting mechanical properties are as welded or bonded together (Figure 14). Fracture propagation in bounded, layered materials, where the layers have different mechanical properties, has received much attention in the engineering literature (Daneshy, 1978; He and Hutchinson, 1989; Hutchinson and Suo, 1992; Valko and Economides, 1995). In the geological literature there has been considerable discussion of arrest by ductile or semiductile layers within stiff layers, but the effects of differences in stiffnesses (Young's moduli) between bounded stiff layers have received comparatively little attention (Bonafede and Rivalta, 1999a,b; Zhang et al., 2007).

For the models (Figures 11, 14), constant fluid overpressure is applied to the hydrofracture along its entire length. However, in nature the tip of a hydrofracture commonly propagates ahead of its fluid front (Valko and Economides, 1995; Economides and Nolte, 2000). This is demonstrated by hydraulic fracture experiments and models which indicate that the fluid front normally lags behind the hydrofracture tip (Warpinski, 1985; Advani et al., 1997; Yew, 1997; Garagash and Detournay, 2000). We have run other numerical models where the part of the hydrofracture close to its tip is without any loading, whereas the hydrofracture was allowed to open along an internal spring of low stiffness (e.g., Brenner and Gudmundsson, 2002, 2004a,b; Gudmundsson et al., 2002). Such a loading represents zero overpressure that is, a situation where the fluid pressure in the hydrofracture is in lithostatic equilibrium with the surrounding rocks.

A constant fluid overpressure, as applied in the numerical models here (Figures 11, 14) implies that, since the stress normal to the fracture normally increases downwards (as the lithostatic pressure does), the total fluid pressure must increase in the same way. Exceptions could occur in a strongly layered crust where the local stresses normal to the fracture would not increase gradually with depth (cf. Haimson and Rummel, 1982; Warpinski et al., 1982). In nature the fluid overpressure would normally increase upwards for fluids with a density $\rho_{f}$ less than the rock density $\rho_{r}$, such as water, due to the buoyancy effect (Equation 4), but decrease upwards for fluids with a high density $\rho_{f}$, such as some mafic magmas. Consequently, in our numerical models we explore the average effect when $\rho_{f}=\rho_{r}$. Models of hydrofracture propagation with linearly varying overpressure distributions give similar solutions and essentially lead to the same conclusions (Gudmundsson and Brenner, 2001; Brenner and Gudmundsson, 2002; Gudmundsson et al., 2002).

Analytical models (Isida, 1955) and numerical models of hydrofractures in homogeneous, isotropic rocks (Figure 11) show that the tensile stress concentration at the surface, or an interface, induced by a propagating fracture has two peaks (Pollard and Segall, 1987). Where the stress peaks are the most likely locations for induced offset fractures at weak interfaces. In the models, the location of the peak is given as a factor of the horizontal distance in comparison to the distance to the hydrofracture tip below the surface ("surface distance"). For the homogenous, isotropic model (Figure 11C), the peak stress is $4 \mathrm{MPa}$ and occurs at a surface distance of 1.6. At a weak contact, such peak stresses, in the order of common in situ tensile strengths, could be high enough to induce offset fractures. Mechanical layering, particularly horizontal discontinuities, may transfer the stress peaks at the surface, so that straightforward inversion of surface geodetic data may lead to unreliable inferred depths of hydrofracture tips (cf. Gudmundsson, 2006).

For fluid overpressure as the only loading, the soft layer would normally act as a stress barrier and thus favor hydrofracture arrest (Figure 14; Brenner and Gudmundsson, 2002, 2004a,b; Larsen and Gudmundsson, 2010). In a reservoir subject to remote compression or tension, however, the results may be very different. When a layered reservoir is subject to horizontal tension, the tensile stresses that concentrate in the stiff layers are expected to be even higher, whereas soft layers still tend to be stress barriers (Gudmundsson and Brenner, 2001). When such a reservoir is subject to horizontal compression, however, the stiff layers are likely to take up most of the compressive stress and act as barriers to vertical hydrofracture propagation (Gudmundsson and Brenner, 2001). Thus, stiff layers are stress barriers in remote compression, whereas soft layers are stress barriers in remote tension or when fluid overpressure is the only loading. Extension of a sedimentary basin leads to relative tension that is, reduction in compression. The relative tensile stresses concentrate in the stiff layers but not in the soft layers which, thereby, may have higher compressive stresses than the stiff layers and thus form stress barriers. This effect is well-known in the petroleum industry (Economides and Nolte, 2000).

Because of possible flow channeling along the widest parts of a fracture (Wang, 1991; Tsang and Neretnieks, 1998), aperture variation is important for the permeability in fluid reservoirs. When fluid overpressure of the hydrofracture is the only loading, or the reservoir is subject to remote compression, the aperture of a vertical hydrofracture is greatest in the soft layers and least in the stiff layers (Brenner and Gudmundsson, 2002; Larsen and Gudmundsson, 2010; Gudmundsson et al., 2012). However, field observations in layered rocks indicate that in soft layers many hydrofractures are shear fractures. This has been observed, for example, for layered carbonate rocks in England (Figure 15; Brenner and Gudmundsson, 2004a,b. There, calcite veins and joints mostly follow inclined shear fractures in the soft shale layers between limestone layers, where they are extension fractures. This indicates that, during hydrofracture formation, the shale had no tensile strength and failed in shear rather than in extension. Because inclined fractures are not longer perpendicular to the minimum principal compressive stress, $\sigma_{3}$, but normal to a higher stress $\sigma_{n}$, they normally are thinner than similar-sized extension fractures.

The cubic law for fluid transport in rock fractures may not apply to fractures with rough walls, or where the aperture varies much along the fracture path. For elastic host rocks the aperture normally depends on the fluid pressure in the fracture, the state of stress in the rock, and the mechanical properties of the host rocks. For fractures with varying aperture, fluid flow may be channeled along their widest parts or greatest openings (Wang, 1991; Tsang 


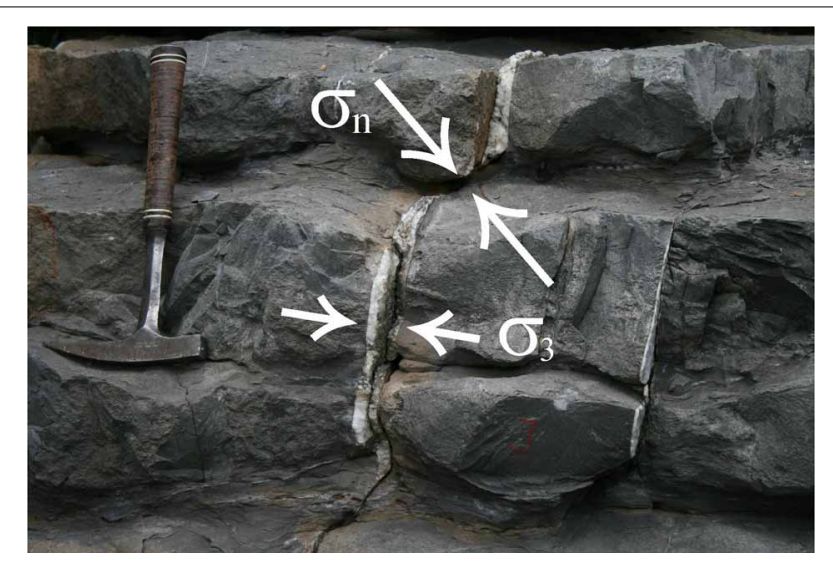

FIGURE 15 | Aperture variation of a calcite vein at Kilve, Somerset Coast. In the gray limestone layer, the vein is a vertical extension fracture, with the minimum principal compressive stress $\sigma_{3}$ as its normal stress (as is indicated by arrows). In the marl layer, however, the vein is an inclined shear fracture, subject to a higher normal stress $\sigma_{n}$ and therefore thinner than the vertical part. View north; the hammer provides a scale (cf. Brenner and Gudmundsson, 2004a). and Neretnieks, 1998; Gudmundsson, 2011a). However, for such realistic fracture geometries, the Navier-Stokes equations have not yet been solved (cf. Zimmerman and Yeo, 2000).

Our field observations (Figure 12) and numerical model (Figure 14) indicate that, although shallow fractures may be more likely to be stratabound than fractures at deeper crustal levels (Odling et al., 1999; Gillespie et al., 2001), hydrofractures can become arrested at any crustal depth if there is a strong contrast in the mechanical properties of adjacent rock layers. This conclusion is supported by the observation that hydraulic fractures in petroleum engineering are commonly arrested at depths of several kilometers (Valko and Economides, 1995; Yew, 1997; Economides and Nolte, 2000). Very many fractures, such as joints and veins, tend to be restricted to single layers, particularly if the contacts between the layers are discontinuities or sites of abrupt changes in mechanical properties. Fracture restriction is also reflected in the commonly observed inverse correlation between joint frequency and layer thickness (Ladeira and Price, 1981; Nelson, 1985; Price and Cosgrove, 1990; Narr and Suppe, 1991; Wu and Pollard, 1995; Ji et al., 1998).

In a layered crust, individual layers with different mechanical properties become differently stressed as a result of remote tension or compression, fluid excess pressure in a reservoir, or the fracture-tip stresses of propagating hydrofractures (Amadei and Stephansson, 1997; Zang and Stephansson, 2010). For example, Haimson and Rummel (1982) measured large variations in the horizontal stresses in lava flows, and in petroleum reservoirs varying horizontal stresses are common (Engelder, 1993; Aguilera, 1995; Economides and Nolte, 2000). These heterogeneous local stress fields associated with mechanically layered rocks control hydrofracture propagation, or arrest, respectively. Through the injection of hydrofractures, as well as through faulting, however, the stress field may be gradually homogenized so that the probability of hydrofracture arrest decreases (Gudmundsson and
Brenner, 2001). Also, host-rock alteration and diagenetic reactions such as mineral transitions, precipitation (cementation) and pressure solution and mechanical compaction may increase the stiffness of primarily soft layers, or soften primarily stiff layers, so that the stiffnesses of adjacent rock layers may gradually become more and more similar. Contacts may become sealed by similar processes so that the reservoir gradually becomes more homogeneous. Then, a multilayer that originally had contrasting properties may eventually behave mechanically as a single layer at the scale of propagating hydrofractures. The reservoir may still consist of different rock layers that can be clearly distinguished, but if the mechanical properties converge, propagating hydrofractures will not longer "feel" these differences. It is only the mechanical layering that affects hydrofracture emplacement. It follows that the conditions for hydrofracture emplacement, and thus the permeability of a reservoir, may change significantly with time.

\section{AUTHOR CONTRIBUTIONS}

Sonja L. Philipp structured the manuscript, selected the figures, and wrote most of the text. Filiz Afşar provided field data, some figures, and revised the text. Agust Gudmundsson wrote parts of the text and revised the entire text.

\section{ACKNOWLEDGMENTS}

This work was funded by a PhD-Grant from Statoil through the University of Bergen, Norway, by the Dorothea-Erxleben Programme of the State of Lower Saxony, and the Deutsche Forschungsgemeinschaft. We thank Marco Neri and Shigekazu Kusumoto for very thorough and helpful comments and Valerio Acocella for efficient editing. Comments by Adelina Geyer and Paul Gillespie on an earlier version are also acknowledged.

\section{REFERENCES}

Adler, P. M., Thovert, J.-F., and Mourzenko, V. V. (2012). Fractured Porous Media. Oxford: Oxford University Press. doi: 10.1093/acprof:oso/9780199666515.001.0001

Advani, S. H., Lee, T. S., Dean, R. H., Pak, C. K., and Avasthi, J. M. (1997). Consequences of fluid lag in three-dimensional hydraulic fractures. Int. J. Numer. Anal. Methods Geomech. 21, 229-240. doi: 10.1002/(SICI)10969853(199704)21:4<229::AID-NAG862>3.0.CO;2-V

Afrouz, A. A. (1992). Practical Handbook of Rock Mass Classification Systems and Modes of Ground Failure. London: CRC Press.

Aguilera, R. (1995). Naturally Fractured Reservoirs. Tulsa, OK: PennWell Publishing Company.

Aguilera, R. (2000). Well test analysis of multi-layered naturally fractured reservoirs. J. Can. Petrol. Techn. 39, 31-37. doi: 10.2118/01-12-TN2

Al-Busaidi, A., Hazzard, J. F., and Young, R. P. (2005). Distinct element modeling of hydraulically fractured Lac du Bonnet granite. J. Geophys. Res. 110, B06302. doi: 10.1029/2004JB003297

Amadei, B., and Stephansson, O. (1997). Rock Stress and its Measurement. London: Chapman and Hall. doi: 10.1007/978-94-011-5346-1

Atkins, A. G., and Mai, Y. W. (1985). Elastic and Plastic Fracture. Chichester: Horwood.

Aydin, A. (2000). Fractures, faults, and hydrocarbon entrapment, migration and flow. Mar. Petrol. Geol. 17, 797-814. doi: 10.1016/S0264-8172(00)00020-9

Baer, G. (1991). Mechanisms of dike propagation in layered rocks and in massive, porous sedimentary rocks. J. Geophys. Res. 96, 11911-11929. doi: 10.1029/91JB00844

Barton, C. A., Zoback, M. D., and Moos, D. (1995). Fluid flow along potentially active faults in crystalline rock. Geology 23, 683-686. doi: 10.1130/00917613(1995)023<0683:FFAPAF $>2.3$.CO;2 
Bear, J. (1993). "Modelling flow and contaminant transport in fractured rocks," in Flow and Contaminant Transport in Fractured Rock, eds J. Bear, C. F. Tsang, and G. de Marsily (New York, NY: Academic Press), 1-37. doi: 10.1016/B978-012-083980-3.50005-X

Becerril, L., Galindo, I., Gudmundsson, A., and Morales, J. M. (2013). Depth of origin of magma in eruptions. Sci. Rep. 3:2762. doi: 10.1038/srep02762

Becker, A., and Gross, M. R. (1996). Mechanism for joint saturation in mechanically layered rocks: an example from southern Israel. Tectonophysics 257, 223-237. doi: 10.1016/0040-1951(95)00142-5

Bell, F. G. (2000). Engineering Properties of Soils and Rocks. 4th Edn. Oxford: Blackwell.

Berkowitz, B. (2002). Characterizing flow and transport in fractured geological media: a review. Adv. Water Res. 25, 861-884. doi: 10.1016/S03091708(02)00042-8

Bonafede, M., and Danesi, S. (1997). Near-field modifications of stress induced by dyke injection at shallow depth. Geophys. J. Int. 130, 435-448. doi: 10.1111/j.1365-246X.1997.tb05659.x

Bonafede, M., and Rivalta, E. (1999a). On tensile cracks close to and across the interface between two welded elastic half-spaces. Geophys. J. Int. 138, 410-434. doi: 10.1046/j.1365-246X.1999.00880.x

Bonafede, M., and Rivalta, E. (1999b). The tensile dislocation problem in a layered elastic medium. Geophys. J. Int. 136, 341-356. doi: 10.1046/j.1365246X.1999.00645.x

Bons, P. D. (2001). The formation of large quartz veins by rapid ascent of fluids in mobile hydrofractures. Tectonophysics 336, 1-17. doi: 10.1016/S00401951(01)00090-7

Bons, P. D., Elburg, M. A., and Gomez-Rivas, E. (2012). A review of the formation of tectonic veins and their microstructures. J. Struct. Geol. 43, 33-62. doi: 10.1016/j.jsg.2012.07.005

Bourbiaux, B. (2010). Fractured reservoir simulation: a challenging and rewarding issue. Oil Gas Sci.Technol. 65, 227-238. doi: 10.2516/ogst/ 2009063

Brebbia, C. A., and Dominguez, J. (1992). Boundary Elements: an Introductory Course. 2nd Edn. Boston, MA: Computational Mechanics. doi: 10.1016/09557997(92)90118-Q

Brenner, S. L. (2003). Field Studies and Models of Hydrofractures in Heterogeneous Reservoirs. Ph.D. thesis, University of Bergen, Bergen, Norway.

Brenner, S. L., and Gudmundsson, A. (2002). Permeability development during hydrofracture propagation in layered reservoirs. Norges Geolog. Undersøkelse Bull. 439, 71-77. Available online at: http://www.ngu.no/upload/Publikasjoner/Bulletin/Bulletin439_71-77.pdf

Brenner, S. L., and Gudmundsson, A. (2004a). "Permeability in layered reservoirs: field examples and models on the effects of hydrofracture propagation," in Coupled Thermo-Hydro-Mechanical-Chemical Processes in Geo-Systems, GeoEngineering Series, Vol. 2. eds O. Stephansson, J. A. Hudson, and L. Jing (Amsterdam: Elsevier), 643-648.

Brenner, S. L., and Gudmundsson, A. (2004b). Arrest and Aperture Variation of Hydrofractures in Layered Reservoirs. Vol. 231. London: Geological Society, Special Publications. doi: 10.1144/GSL.SP.2004.231.01.08

Broberg, K. B. (1999). Cracks and Fracture. London: Academic Press.

Brooks, C. R., and Choudhury, A. (2002). Failure Analysis of Engineering Materials. New York, NY: McGraw-Hill.

Bruhn, R. L., Parry, W. T., Yonkee, W. A., and Thompson, T. (1994). Fracturing and hydrothermal alteration in normal fault zones. Pure Appl. Geophys. 142, 609-644. doi: 10.1007/BF00876057

Caine, J. S., Evans, J. P., and Forster, C. B. (1996). Fault zone architecture and permeability structure. Geology 24, 1025-1028. doi: 10.1130/00917613(1996)024<1025:FZAAPS > 2.3.CO;2

Chapman, R. E. (1981). Geology and Water: An Introduction to Fluid Mechanics for Geologists. London: Nijhoff. doi: 10.1007/978-94-009-8244-4

Charlez, P. A. (1997). Rock Mechanics, Vol. 2. Petroleum Applications. Paris: Editions Technip.

Chester, F. M., and Logan, J. M. (1986). Implications for mechanical properties of brittle faults from observations of the Punchbowl fault zone, California. Pure Appl. Geophys. 124, 79-106. doi: 10.1007/BF00875720

Chiaramonte, L., Zoback, M. D., Friedmann, J., and Stamp, V. (2008). Seal integrity and feasibility of $\mathrm{CO} 2$ sequestration in the Teapot Dome EOR pilot: geomechanical site characterization. Environ. Geol. 54, 1667-1675. doi: 10.1007/s00254007-0948-7
Chilingar, G. V., Serebryakov, V. A., and Robertson, J. O. (2002). Origin and Prediction of Abnormal Formation Pressures. London: Elsevier.

Cobbing, J., and O’Dochartaigh, B. E. (2007). Hydrofracturing water boreholes in hard rock aquifers in Scotland. Q. J. Eng. Geol. Hydrogeol. 40, 181-186. doi: 10.1144/1470-9236/06-018

Cook, J., and Gordon, J. E. (1964). A mechanism for the control of crack growth in all-brittle systems. Proc. R. Soc. Lond. A 282, 508-520. doi: 10.1098/rspa.1964.0248

Cooke, M. L., and Underwood, C. A. (2001). Fracture termination and step-over at bedding interfaces due to frictional slip and interface opening. J. Struct. Geol. 23, 223-238. doi: 10.1016/S0191-8141(00)00092-4

Coward, M. P., Daltaban, T. S., and Johnson, H. (eds.). (1998). Structural Geology in Reservoir Characterization. Vol. 127. London: Geological Society, Special Publications.

Dahlberg, E. C. (1994). Applied Hydrodynamics in Petroleum Exploration. New York, NY: Springer.

Dahm, T. (2000). Numerical simulations of the propagation path and the arrest of fluid-filled fractures in the Earth. Geophys. J. Int. 141, 623-638. doi: 10.1046/j.1365-246x.2000.00102.x

Dahm, T., Hainzl, S., and Fischer, T. (2010). Bidirectional and unidirectional fracture growth during hydrofracturing: role of driving stress gradients. J. Geophys. Res. 115, B12322. doi: 10.1029/2009JB006817

Daneshy, A. A. (1978). Hydraulic fracture propagation in layered formations. AIME Soc. Petrol. Eng. J. 18, 33-41. doi: 10.2118/6088-PA

Daniel, I. M., and Ishai, O. (1994). Engineering Mechanics of Composite Materials. Oxford: Oxford University Press.

Davis, G. H., and Reynolds, S. J. (1996). Structural Geology of Rocks and Regions. New York, NY: Wiley.

Davis, P. M. (1983). Surface deformation associated with a dipping hydrofracture. J. Geophys. Res. 88, 5826-5834. doi: 10.1029/JB088iB07p05826

Davison, I. (1995). Fault slip evolution determined from crack-seal veins in pull-aparts and their implications for general slip models. J. Struct. Geol. 17, 1025-1034. doi: 10.1016/0191-8141(94)00131-I

de Marsily, G. (1986). Quantitative Hydrogeology. New York, NY: Academic Press.

Deming, D. (2002). Introduction to Hydrogeology. Boston, MA: McGraw-Hill.

Dietrich, P., Helmig, R., Sauter, M., Hötzl, H., and Köngeter, J., Teutsch, G. (eds.). (2005). Flow and Transport in Fractured Porous Media. Berlin: Springer. doi: $10.1007 / \mathrm{b} 138453$

Dresen, G., Stephansson, O., and Zang, A. (2006). Rock damage and fluid transport, part I. Pure Appl. Geophys. 163, 1-278. doi: 10.1007/s00024-006-0062-x

Economides, M. J., and Boney, C. (2000). "Reservoir stimulation in petroleum production," in Reservoir Stimulation, eds M. J. Economides and K. G. Nolte (New York, NY: Wiley), 1-1, 1-30.

Economides, M. J., and Nolte, K. G. (eds.). (2000). Reservoir Stimulation. New York, NY: Wiley.

Engelder, T. (1993). Stress Regimes in the Lithosphere. Princeton, NJ: Princeton University Press.

Evans, J. P., Forster, C. B., and Goddard, J. V. (1997). Permeability of fault-related rocks, and implications for hydraulic structure of fault zones. J. Struct. Geol. 19, 1393-1404. doi: 10.1016/S0191-8141(97)00057-6

Farmer, I. (1983). Engineering Behaviour of Rocks. London: Chapman and Hall.

Faulkner, D. R., Jackson, C. A. L., Lunn, R. J., Schlische, R. W., Shipton, Z. K., Wibberley, C. A. J., et al. (2010). A review of recent developments concerning the structure, mechanics and fluid flow properties of fault zones. J. Struct. Geol. 32, 1557-1575. doi: 10.1016/j.jsg.2010.06.009

Faybishenko, B., Witherspoon, P. A., and Benson, S. M. (2000). Dynamics of Fluids in Fractured Rocks. New York, NY: Wiley. doi: 10.1029/GM122

Finkbeiner, T., Barton, C. A., and Zoback, M. D. (1997). Relationships among insitu stress, fractures and faults, and fluid flow: monterey formation, Santa Maria basin, California. Am. Assoc. Petrol. Geol. Bull. 81, 1975-1999.

Flekkoy, E. G., Malthe-Sorenssen, A., and Jamtveit, B. (2002). Modeling hydrofracture. J. Geophys. Res. 107, 2151. doi: 10.1029/2000JB000132

Fyfe, W. S., Price, N. J., and Thompson, A. B. (1978). Fluids in the Earth's Crust. London: Elsevier.

Garagash, D., and Detournay, E. (2000). The tip region of a fluid-driven fracture in an elastic medium. J. Appl. Mech. 67, 183-192. doi: 10.1115/1.321162

Geshi, N., Kusumoto, S., and Gudmundsson, A. (2010). The geometric difference between feeder and non-feeder dikes. Geology 38, 195-198. doi: $10.1130 / \mathrm{G} 30350.1$ 
Gillespie, P. A., Walsh, J. J., Watterson, J., Bonson, C. G., and Manzocchi, T. (2001). Scaling relationships of joint and vein arrays from The Burren, Co Clare, Ireland. J. Struct. Geol. 23, 183-201. doi: 10.1016/S0191-8141(00) 00090-0

Goodman, R. E. (1989). Introduction to Rock Mechanics. New York, NY: Wiley.

Grecksch, G., Roth, F., and Kümpel, H. J. (1999). Coseismic well-level changes due to the 1992 Roermond earthquake compared to static deformation of half-space solutions. Geophys. J. Int. 138, 470-478. doi: 10.1046/j.1365-246X.1999.00894.x

Gudmundsson, A. (1999). Fluid overpressure and stress drop in fault zones. Geophys. Res. Lett. 26, 115-118. doi: 10.1029/1998GL900228

Gudmundsson, A. (2000a). Active fault zones and groundwater flow. Geophys. Res. Lett. 27, 2993-2996. doi: 10.1029/1999GL011266

Gudmundsson, A. (2000b). Fracture dimensions, displacements and fluid transport. J. Struct. Geol. 22, 1221-1231. doi: 10.1016/S0191-8141(00)00052-3

Gudmundsson, A. (2006). How local stresses control magma-chamber ruptures, dyke injections, and eruptions in composite volcanoes. Earth Sci. Rev. 79, 1-31. doi: 10.1016/j.earscirev.2006.06.006

Gudmundsson, A. (2011a). Rock Fractures in Geological Processes. Cambridge, UK: Cambridge University Press. doi: 10.1017/CBO9780511975684

Gudmundsson, A. (2011b). Deflection of dykes into sills at discontinuities and magma-chamber formation. Tectonophysics 500, 50-64. doi: 10.1016/j.tecto.2009.10.015

Gudmundsson, A., and Brenner, S. L. (2001). How hydrofractures become arrested. Terra Nova 13, 456-462. doi: 10.1046/j.1365-3121.2001.00380.x

Gudmundsson, A., and Brenner, S. L. (2005). On the conditions of sheet injections and eruptions in stratovolcanoes. Bull. Volcanol. 67, 768-782. doi: 10.1007/s00445-005-0433-7

Gudmundsson, A., Fjeldskaar, I., and Brenner, S. L. (2002). Propagation pathways and fluid transport of hydrofractures in jointed and layered rocks in geothermal fields. J. Volcanol. Geotherm. Res. 116, 257-278. doi: 10.1016/S03770273(02)00225-1

Gudmundsson, A., Kusumoto, S., Simmenes, T. H., Philipp, S. L., Larsen, B., and Lotveit, I. F. (2012). Effects of overpressure variations on fracture apertures and fluid transport. Tectonophysics 581, 220-230. doi: 10.1016/j.tecto.2012.05.003

Gudmundsson, A., and Philipp, S. L. (2006). How local stresses prevent volcanic eruptions. J. Volcanol. Geotherm. Res. 158, 257-268. doi: 10.1016/j.jvolgeores.2006.06.005

Gudmundsson, A., Simmenes, T. H., Larsen, B., and Philipp, S. L. (2010). Effects of internal structure and local stresses on fracture propagation, deflection, and arrest in fault zones. J. Struct. Geol. 32, 1643-1655. doi: 10.1016/j.jsg.2009.08.013

Gulrajani, S. N., and Nolte, K. G. (2000). "Fracture evaluation using pressure diagnostics," in Reservoir Stimulation, eds M. J. Economides and K. G. Nolte (New York, NY: Wiley), 9-1, 9-63.

Gundersen, E., Flekkoy, E. G., Bjorlykke, K., Feder, J., and Jamtveit, B. (2011). Fracture spacing during hydro-fracturing of cap-rocks. Geofluids 11, 280-293. doi: 10.1111/j.1468-8123.2011.00338.x

Haimson, B. C., and Rummel, F. (1982). Hydrofracturing stress measurements in the Iceland research drilling project drill hole at Reydarfjordur, Iceland. J. Geophys. Res. 87, 6631-6649. doi: 10.1029/JB087iB08p06631

Haneberg, W. C., Mozley, P. S., Moore, J. C., and Goodwin, L. B. (eds.). (1999). Faults and Subsurface Fluid Flow in the Shallow Crust. Washington, DC: American Geophysical Union. doi: 10.1029/GM113

Hardebeck, J. L., and Hauksson, E. (1999). Role of fluids in faulting inferred from stress field signatures. Science 285, 236-239. doi: 10.1126/science.285.5425.236

Hatheway, A. W., and Kiersch, G. A. (1982). "Engineering properties of rocks," in Handbook of Physical Properties of Rocks, ed R. S. Carmichael (Boca Raton, FL: CRC Press), 289-331.

He, M. Y., and Hutchinson, J. W. (1989). Crack deflection at an interface between dissimilar elastic materials. Int. J. Solids Struct. 25, 1053-1067. doi: 10.1016/0020-7683(89)90021-8

Heffer, K. J., Fox, R. J., McGill, C. A., and Koutsabeloulis, N. C. (1997). Novel techniques show links between reservoir flow directionality, earth stress, fault structure and geomechanical changes in mature waterfloods. SPE J. 2, 91-98. doi: 10.2118/30711-PA

Heimpel, M., and Olson, P. (1994). "Buoyancy-driven fracture and magma transport through the lithosphere: models and experiments," in Magmatic Systems, ed M. P. Ryan (London: Academic Press), 223-240. doi: 10.1016/S00746142(09)60098-X
Helgeson, D. E., and Aydin, A. (1991). Characteristics of joint propagation across layer interfaces in sedimentary rocks. J. Struct. Geol. 13, 897-911. doi: 10.1016/0191-8141(91)90085-W

Heuze, F. E. (1980). Scale effects in the determination of rock mass strength and deformability. Rock Mech. 12, 167-192. doi: 10.1007/BF01251024

Hubbert, M. K., and Rubey, W. W. (1959). Role of fluid pressure in mechanics of overthrust faulting Part I. Geol. Soc. Am. Bull. 70, 115-166. doi: 10.1130/00167606(1959)70[115:ROFPIM]2.0.CO;2

Hubbert, M. K., and Willis, D. G. (1957). Mechanics of hydraulic fracturing. Trans. Am. Inst. Min. Metall. Petrol. Eng. 210, 153-168.

Hudson, J. A., and Harrison, J. P. (1997). Engineering Rock Mechanics: an Introduction to the Principles. Oxford, UK: Pergamon.

Hutchinson, J. W., and Suo, Z. (1992). Mixed-mode cracking in layered materials. Adv. Appl. Mech. 29, 63-191. doi: 10.1016/S0065-2156(08)70164-9

Ingebritsen, S. E., and Sanford, W. E. (1998). Groundwater in Geologic Processes. Cambridge: Cambridge University Press.

Isida, M. (1955). On the Tension of a Semi-Infinite Plate with an Elliptic Hole. Technical Report of the Faculty of Engineering, Tokushina University, Vol. 5, 75-95.

Jaeger, J. C., and Cook, N. G. W. (1979). Fundamentals of Rock Mechanics. London: Chapman and Hall.

Ji, S. C., Zhu, Z. M., and Wang, Z. C. (1998). Relationship between joint spacing and bed thickness in sedimentary rocks: effects of interbed slip. Geol. Mag. 135, 637-655. doi: 10.1017/S0016756898001459

Jones, G., Fisher, Q. J., and Knipe, R. J. (eds.). (2008). Faulting and Fault Sealing in Hydrocarbon Reservoirs. Vol. 147. London: Geological Society, Special Publications.

Jumikis, A. R. (1979). Rock Mechanics. Clausthal: Trans Tech Publications.

Kim, J. W., Bhowmick, S., Hermann, I., and Lawn, B. R. (2006). Transverse fracture in brittle bilayers: relevance for failure of all-ceramic dental crowns. J. Biomed. Mater. Res. B Appl. Biomater. 79B, 58-65. doi: 10.1002/jbm.b.30511

King, C. Y., Azuma, S., Igarashi, G., Ohno, M., Saito, H., and Wakita, H. (1999). Earthquake-related water-level changes at 16 closely clustered wells in Tono, central Japan. J. Geophys. Res. 104, 13073-13082. doi: 10.1029/1999JB900080

Kümpel, H. J. (ed.). (2003). Thermo-Hydro-Mechanical Coupling in Fractured Rock. Berlin: Birkhäuser. doi: 10.1007/978-3-0348-8083-1

Kusumoto, S., Geshi, N., and Gudmundsson, A. (2013a). Aspect ratios and magma overpressures of non-feeder dikes observed in the Miyake-jima volcano (Japan), and fracture toughness of its upper part. Geophys. Res. Lett. 40, 1065-1068. doi: $10.1002 /$ grl.50284

Kusumoto, S., Gudmundsson, A., Simmenes, T. H., Geshi, N., and Philipp, S. L. (2013b). Inverse modeling for estimating fluid-overpressure distributions and stress intensity factors from an arbitrary open-fracture geometry. J. Struct. Geol. 46, 92-98. doi: 10.1016/j.jsg.2012.10.004

Labaume, P., Craw, D., Lespinasse, M., and Muchez, P. (eds.). (2002). Tectonic processes and the flow of mineralising fluids. Tectonophysics 348, 1-185. doi: 10.1016/S0040-1951(01)00245-1

Ladeira, F. L., and Price, N. J. (1981). Relationship between fracture spacing and bed thickness. J. Struct. Geol. 3, 179-183. doi: 10.1016/0191-8141(81)90013-4

Larsen, B., Grunnaleite, I., and Gudmundsson, A. (2008). How fracture systems affect permeability development in shallow-water carbonate rocks: an example from the Gargano Peninsula, Italy. J. Struct. Geol. 32, 1212-1230. doi: 10.1016/j.jsg.2009.05.009

Larsen, B., and Gudmundsson, A. (2010). Linking of fractures in layered rocks: Implications for permeability. Tectonophysics 492, 108-120. doi: 10.1016/j.tecto.2010.05.022

Lee, C. H., and Farmer, I. (1993). Fluid Flow in Discontinuous Rocks. London: Chapman and Hall.

Lee, J. J.-W., Lloyd, I. K., Chai, H., Jung, Y.-G., and Lawn, B. R. (2007). Arrest, deflection, penetration and reinitiation of cracks in brittle layers across adhesive interlayers. Acta Mater. 55, 5859-5866. doi: 10.1016/j.actamat.2007.06.038

Lister, J. R., and Kerr, R. C. (1991). Fluid-mechanical models of crack propagation and their application to magma transport in dykes. J. Geophys. Res. 96, 10049-10077. doi: 10.1029/91JB00600

Lonergan, L., Jolly, R. J. H., Rawnsley, K., and Sanderson, D. J. (eds.). (2007). Fractured Reservoirs. Vol. 270. London: Geological Society, Special Publications.

Mahrer, K. D. (1999). A review and perspective on far-field hydraulic fracture geometry studies. J. Petr. Sci. Eng. 24, 13-28. doi: 10.1016/S09204105(99)00020-0 
Mandl, G. (2005). Rock Joints: The Mechanical Genesis. Berlin: Springer.

Mandl, G., and Harkness, R. M. (1987). "Hydrocarbon migration by hydraulic fracturing," in Deformation of Sediments and Sedimentary Rocks, Vol. 29, eds M. E. Jones and R. M. E. Preston (London: Geological Society of London, Special Publication), 39-53. doi: 10.1144/GSL.SP.1987.029.01.04

Martí, J., and Geyer, A. (2009). Central vs flank eruptions at Teide-Pico Viejo twin stratovolcanoes (Tenerife, Canary Islands). J. Volcanol. Geotherm. Res. 181, 47-60. doi: 10.1016/j.jvolgeores.2008.12.010

Maugis, D. (2000). Contact, Adhesion and Rupture of Elastic Solids. Berlin: Springer. doi: 10.1007/978-3-662-04125-3

McCaffrey, K. J. W., Lonergan, L. and Wilkinson, J. J. (eds.). (1999). Fractures, Fluid Flow and Mineralization. Vol. 155. London: Geological Society of London Special Publication.

Muirwood, R., and King, G. C. P. (1993). Hydrological signatures of earthquake strain. J. Geophys. Res. 98, 22035-22068. doi: 10.1029/93JB02219

Naceur, K. B., and Touboul, E. (1990). Mechanisms controlling fracture-height growth in layered media. SPE Prod. Eng. 5, 142-150. doi: 10.2118/16433-PA

Narr, W., and Suppe, J. (1991). Joint spacing in sedimentary rocks. J. Struct. Geol. 13, 1037-1048. doi: 10.1016/0191-8141(91)90055-N

Nasseri, M. H. B., Mohanty, B., and Young, R. P. (2006). Fracture toughness measurements and acoustic emission activity in brittle rocks. Pure Appl. Geophys. 163, 917-945. doi: 10.1007/s00024-006-0064-8

Nelson, R. A. (1985). Geologic Analysis of Naturally Fractured Reservoirs. Houston, TX: Gulf Publishing.

Nelson, R. A. (2001). Geologic Analysis of Naturally Fractured Reservoirs. 2nd Edn. London: Butterworth-Heinemann.

Neuzil, C. E. (2003). Hydromechanical coupling in geologic processes. Hydrogeol. J. 11, 41-83. doi: 10.1007/s10040-002-0230-8

Nunn, J. A., and Meulbroek, P. (2002). Kilometer-scale upward migration of hydrocarbons in geopressured sediments by buoyancy-driven propagation of methane filled fractures. Am. Assoc. Petrol. Geol. Bull. 86, 907-918. doi: 10.1306/61EEDBD4-173E-11D7-8645000102C1865D

Odling, N. E., Gillespie, P., Bourgine, B., Castaing, C., Chiles, J. P., Christensen, N. P., et al. (1999). Variations in fracture system geometry and their implications for fluid flow in fractured hydrocarbon reservoirs. Petrol. Geosci. 5, 373-384. doi: 10.1144/petgeo.5.4.373

Osborne, M. J., and Swarbrick, R. E. (1997). Mechanisms for generating overpressure in sedimentary basins: a reevaluation. Am. Assoc. Petrol. Geol. Bull. 81, 1023-1041.

Paterson, M. S. (1978). Experimental Rock Deformation: The Brittle Field. Berlin: Springer. doi: 10.1007/978-3-662-11720-0

Peterson, R. E. (1974). Stress Concentration Factors. New York, NY: Wiley.

Philipp, S. L. (2008). Geometry and formation of gypsum veins in mudstones at Watchet, Somerset, SW-England. Geol. Mag. 145, 831-844. doi: $10.1017 /$ S001675 6808005451

Philipp, S. L. (2012). Fluid overpressure of mineral veins at Kilve, Somerset, SW England, Tectonophysics 581, 35-47. doi: 10.1016/j.tecto.2012.01.015

Pollard, D. D., and Segall, P. (1987). “Theoretical displacement and stresses near fractures in rocks: with application to faults, points, veins, dikes, and solution surfaces," in Fracture Mechanics of Rocks, ed B. Atkinson (London: Academic Press), 277-349. doi: 10.1016/B978-0-12-066266-1.50013-2

Price, N. J., and Cosgrove, J. (1990). Analysis of Geological Structures. Cambridge, UK: Cambridge University Press.

Priest, S. D. (1992). Discontinuity Analysis for Rock Engineering. London: Chapman and Hall.

Ray, R., Sheth, H. C., and Mallik, J. (2007). Structure and emplacement of the Nandurbar-Dhule mafic dyke swarm, Deccan Traps, and the tectonomagmatic evolution of flood basalts. Bull. Volcanol. 69, 537-531. doi: 10.1007/s00445-0060089-y

Renshaw, C. E., and Pollard, D. D. (1994). Numerical simulation of fracture set formation - A fracture-mechanics model consistent with experimental observations. J. Geophys. Res. 99, 9359-9372. doi: 10.1029/94JB00139

Rijken, P., and Cooke, M. L. (2001). Role of shale thickness on vertical connectivity of fractures: application of crack-bridging theory to the Austin Chalk, Texas. Tectonophysics 337, 117-133. doi: 10.1016/S0040-1951(01)00107-X

Rijsdijk, K. F., Owen, G., Warren, W. P., McCarroll, D., and van der Meer, J. J. M. (1999). Clastic dykes in over-consolidated tills: evidence for subglacial hydrofracturing at Killiney Bay, eastern Ireland. Sediment. Geol. 129, 111-126. doi: 10.1016/S0037-0738(99)00093-7
Roeloffs, E. A. (1988). Hydrologic precursors to earthquakes - a review. Pure Appl. Geophys. 126, 177-209. doi: 10.1007/BF00878996

Rojstaczer, S., Wolf, S., and Michel, R. (1995). Permeability enhancement in the shallow crust as a cause of earthquake-induced hydrological changes. Nature 373, 237-239. doi: 10.1038/373237a0

Rossmanith, H. P. (ed.). (1998). Mechanics of Jointed and Faulted Rock. Rotterdam: Balkema.

Rubin, A. M. (1995). Propagation of magma-filled cracks. Annu. Rev. Earth Planet. Sci. 23, 287-336. doi: 10.1146/annurev.ea.23.050195.001443

Rummel, F. (1987). "Fracture mechanics approach to hydraulic fracturing stress measurements," in Fracture Mechanics of Rock, ed B. Atkinson (London: Academic Press), 217-239. doi: 10.1016/B978-0-12-066266-1.50011-9

Sahimi, M. (2011). Flow and Transport in Porous Media and Fractured Rock: From Classical Methods to Modern Approaches. New York, NY: Wiley. doi: $10.1002 / 9783527636693$

Savin, G. N. (1961). Stress Concentrations around Holes. London: Pergamon.

Schön, J. H. (2004). Physical Properties of Rocks: Fundamentals and Principles of Petrophysics, 2nd Edn. London: Elsevier.

Schultz, R. A. (1995). Limits on strength and deformation properties of jointed basaltic rock masses. Rock Mech. Rock Eng. 28, 1-15. doi: 10.1007/BF01024770

Secor, D. T. (1965). Role of fluid pressure in jointing. Am. J. Sci. 263, 633-646. doi: 10.2475/ajs.263.8.633

Secor, D. T., and Pollard, D. D. (1975). On the stability of open hydraulic fractures in the earth's crust. Geophys. Res. Lett. 2, 510-513. doi: 10.1029/GL002i011 p00510

Selley, R. C. (1998). Elements of Petroleum Geology. London: Academic Press.

Sibson, R. H. (1996). Structural permeability of fluid-driven fault-fracture meshes. J. Struct. Geol. 18, 1031-1042. doi: 10.1016/0191-8141(96)00032-6

Simonson, E. R., Abou-Sayed, A. S., and Clifton, R. J. (1978). Containment of massive hydraulic fractures. Soc. Petrol. Eng. J. 18, 27-32. doi: 10.2118/6089-PA

Singhal, B. B. S., and Gupta, R. P. (1999). Applied Hydrogeology of Fractured Rocks. London: Kluwer. doi: 10.1007/978-94-015-9208-6

Sleep, N. H., and Fujita, K. (1997). Principles of Geophysics. Oxford, UK: Blackwell. Smart, B. G. D., Somerville, J. M., Edlman, K., and Jones, C. (2001). Stress sensitivity of fractured reservoirs. J. Petrol. Sci. Eng. 29, 29-37. doi: 10.1016/S09204105(00)00088-7

Smith, M. B., and Shlyapobersky, J. W. (2000). "Basics of hydraulic fracturing," in Reservoir Stimulation, eds M. J. Economides and K. G. Nolte (New York, NY: Wiley), 5-1, 5-28.

Smits, A. J. (2000). A Physical Introduction to Fluid Mechanics. New York, NY: Wiley. Sneddon, I. N., and Lowengrub, M. (1969). Crack Problems in the Classical Theory of Elasticity. New York, NY: Wiley.

Spence, D. A., Sharp, P. W., and Turcotte, D. L. (1987). Buoyancy-driven crackpropagation - a mechanism for magma migration. J. Fluid Mech. 174, 135-153. doi: $10.1017 /$ S0022112087000077

Spence, D. A., and Turcotte, D. L. (1985). Magma-driven propagation of cracks. J. Geophys. Res. 90, 575-580. doi: 10.1029/JB090iB01p00575

Spence, G. H., Redfern, J., Aguilera, R., Bevan, T. G., Cosgrove, J. W., Couples, G. D., et al. (2013). Advances in the Study of Fractured Reservoirs. Vol. 374. Geological Society of London, Special Publications. doi: 10.1144/SP374

Stauffer, D., and Aharony, A. (1994). Introduction to Percolation Theory. London: Taylor and Francis.

Stearns, D. W., and Friedman, M. (1972). Reservoirs in fractured rocks. Am. Assoc. Petrol. Geol. Mem. 16, 82-106.

Stewart, M. A., Klein, E. M., Karson, J. A., and Brophy, J. G. (2003). Geochemical relationships between dikes and lavas at the Hess Deep Rift: implications for magma eruptibility. J. Geophys. Res. 108, 2184. doi: 10.1029/2001 JB001622

Sun, R. J. (1969). Theoretical size of hydraulically induced horizontal fractures and corresponding surface uplift in an idealized medium. J. Geophys. Res. 74, 5995-6011. doi: 10.1029/JB074i025p05995

Taylor, W. L., Pollard, D. D., and Aydin, A. (1999). Fluid flow in discrete joint sets: field observations and numerical simulations. J. Geophys. Res. 104, 28983-29006. doi: 10.1029/1999JB900179

Teufel, L. W., and Clark, J. A. (1984). Hydraulic fracture propagation in layered rock: experimental studies of fracture containment. Soc. Petrol. Eng. J. 19-32. doi: 10.2118/9878-PA

Tsang, C. F., and Neretnieks, I. (1998). Flow channeling in heterogeneous fractured rocks. Rev. Geophys. 36, 275-298. doi: 10.1029/97RG03319 
Tvergaard, V., and Hutchinson, J. W. (2008). Mode III effects on interface delamination. J. Mech. Phys. Solids 65, 215-229. doi: 10.1016/j.jmps.2007.04.013

Twiss, R. J., and Moores, E. M. (2006). Structural Geology. 2nd Edn. New York, NY: W.H. Freeman.

Valko, P., and Economides, M. J. (1995). Hydraulic Fracture Mechanics. New York, NY: Wiley.

van der Pluijm, B. A., and Marshak, S. (2003). Earth Structure. 2nd Edn. New York, NY: McGraw Hill

van Eekelen, H. E. M. (1982). Hydraulic fracture geometry: fracture containment in layered formations. Soc. Petrol. Eng. J. 22, 341-349. doi: 10.2118/9261-PA

van Golf-Racht, T. D. (2009). Fundamentals of Fractured Reservoir Engineering. London: Elsevier.

Vermilye, J. M., and Scholz, C. H. (1995). Relation between vein length and aperture. J. Struct. Geol. 17, 423-434. doi: 10.1016/0191-8141(94)00058-8

Vigneresse, J. L. (2001). Fluids and fractures in the lithosphere. Tectonophysics 336, 1-244. doi: 10.1016/S0040-1951(01)00112-3

Wang, J. S. Y. (1991). Flow and transport in fractured rocks. Rev. Geophys. 29, 254-262.

Warpinski, N. R. (1985). Measurement of width and pressure in a propagating hydraulic fracture. J. Soc. Petrol. Eng. 25, 46-54.

Warpinski, N. R., Schmidt, R. A., and Northrop, D. A. (1982). In-situ stress: the predominant influence on hydraulic fracture containment. J. Petrol. Technol. 34, 653-664.

Warpinski, N. R., and Teufel, L. W. (1987). Influence of geologic discontinuities on hydraulic fracture propagation. J. Petrol. Technol. 39, 209-220.

Weertman, J. (1971). Theory of water-filled crevasses in glaciers applied to vertical magma transport beneath oceanic ridges. J. Geophys. Res. 76, 1171-1183. doi: 10.1029/JB076i005p01171

Weertman, J. (1996). Dislocation Based Fracture Mechanics. London: World Scientific. doi: 10.1142/3062

Wu, H. Q., and Pollard, D. D. (1995). An experimental study of the relationship between joint spacing and layer thickness. J. Struct. Geol. 17, 887-905. doi: 10.1016/0191-8141(94)00099-L
Yew, C. H. (1997). Mechanics of Hydraulic Fracturing. Houston, TX: Gulf Publishing.

Zang, A., and Stephansson, O. (2010). Stress Field of the Earth's Crust. Berlin: Springer. doi: 10.1007/978-1-4020-8444-7

Zhang, X., Jeffrey, R. G., and Thiercelin, M. (2007). Deflection and propagation of fluid-driven fractures at frictional bedding interfaces: a numerical investigation. J. Struct. Geol. 29, 396-410. doi: 10.1016/j.jsg.2006. 09.013

Zimmerman, R. W., and Yeo, I.-W. (2000). "Fluid flow in rock fractures: from the navier-stokes equations to the cubic law," in Dynamics of Fluids in Fractured Rock, Geophys. Monograph 122, eds B. Faybishenko, P. A. Witherspoon, and S. M. Benson (Washington, DC: American Geophysical Union), 213-224. doi: 10.1029/GM122p0213

Conflict of Interest Statement: The authors declare that the research was conducted in the absence of any commercial or financial relationships that could be construed as a potential conflict of interest.

Received: 02 November 2013; accepted: 01 December 2013; published online: 20 December 2013.

Citation: Philipp SL, Afşar F and Gudmundsson A (2013) Effects of mechanical layering on hydrofracture emplacement and fluid transport in reservoirs. Front. Earth Sci. 1:4. doi: 10.3389/feart.2013.00004

This article was submitted to Structural Geology and Tectonics, a section of the journal Frontiers in Earth Science.

Copyright (C) 2013 Philipp, Afşar and Gudmundsson. This is an open-access article distributed under the terms of the Creative Commons Attribution License (CC BY). The use, distribution or reproduction in other forums is permitted, provided the original author(s) or licensor are credited and that the original publication in this journal is cited, in accordance with accepted academic practice. No use, distribution or reproduction is permitted which does not comply with these terms. 